Working Paper/Document de travail 2011-19

\title{
Measuring Systemic Importance of Financial Institutions: An Extreme Value Theory Approach
}

by Toni Gravelle and Fuchun Li 
Bank of Canada Working Paper 2011-19

September 2011

\title{
Measuring Systemic Importance of Financial Institutions: An Extreme Value Theory Approach
}

\author{
by \\ Toni Gravelle and Fuchun Li \\ Financial Stability Department \\ Bank of Canada \\ Ottawa, Ontario, Canada K1A OG9 \\ grae@bankofcanada.ca \\ fuchunli@bankofcanada.ca
}

Bank of Canada working papers are theoretical or empirical works-in-progress on subjects in economics and finance. The views expressed in this paper are those of the authors. No responsibility for them should be attributed to the Bank of Canada. 


\section{Acknowledgements}

The authors are grateful to Jorge Chau-Lau, Ian Christensen, James Chapman, JeanMarie Dufour, Alejandro Garcia, Céline Gauthier, Philipp Hartmann, Matthew Pritsker, Yasuo Terajima, Alexander Ueberfeldt, and Chen Zhou for their helpful comments. The authors would also like to thank seminar participants at the Bank of Canada. 


\begin{abstract}
In this paper, we define a financial institution's contribution to financial systemic risk as the increase in financial systemic risk conditional on the crash of the financial institution. The higher the contribution is, the more systemically important is the institution for the system. Based on relevant but different measurements of systemic risk, we propose a set of market-based measures on the systemic importance of financial institutions, each designed to capture certain aspects of systemic risk. Multivariate extreme value theory approach is used to estimate these measures. Using six big Canadian banks as the proxy for Canadian banking sector, we apply these measures to identify systemically important banks in Canadian banking sector and major risk contributors from international financial institutions to Canadian banking sector. The empirical evidence reveals that (i) the top three banks, RBC Financial Group, TD Bank Financial Group, and Scotiabank are more systemically important than other banks, although with different order from different measures, while we also find that the size of a financial institution should not be considered as a proxy of systemic importance; (ii) compared to the European and Asian banks, the crashes of U.S. banks, on average, are the most damaging to the Canadian banking sector, while the risk contribution to the Canadian banking sector from Asian banks is quite lower than that from banks in U.S. and euro area; (iii) the risk contribution to the Canadian banking sector exhibits " home bias ", that is, cross-country risk contribution tends to be smaller than domestic risk contribution.
\end{abstract}

JEL classification: C14, C58, G21, G32

Bank classification: Financial stability; Financial system regulation and policies;

Financial institutions; Econometric and statistical methods

\title{
Résumé
}

Les auteurs définissent la contribution d'une institution financière au risque systémique financier comme la hausse que connaîtrait ce risque si l'institution s'effondrait. Plus l'établissement en question contribue au risque systémique, plus il revêt de l'importance du point de vue du système. En se basant sur différentes mesures pertinentes de ce risque, les auteurs proposent un assortiment d'indicateurs de marché de l'importance systémique des institutions financières, dont chacun rend compte d'aspects distincts du risque systémique et qui sont construits à partir de techniques multivariées inspirées de la théorie des valeurs extrêmes. Armés de ces indicateurs, ils repèrent les institutions d'importance systémique dans le secteur bancaire canadien (ramené aux six principales banques du pays) ainsi que les institutions financières étrangères qui contribuent de façon significative au niveau de risque à l'échelle du secteur. Trois grandes conclusions ressortent de leurs estimations. D'abord, les trois plus grosses banques - RBC Groupe financier, le Groupe Financier Banque TD et la Banque Scotia - ont un poids systémique plus élevé, mais leur classement par ordre d'importance varie selon l'indicateur utilisé; les auteurs constatent par ailleurs que la taille d'un établissement financier n'est pas un 
indice fiable de son importance systémique. Deuxièmement, la faillite d'une banque américaine est, en moyenne, plus dommageable pour le secteur bancaire canadien que celle d'une institution européenne ou asiatique, et la contribution des banques asiatiques au risque est bien inférieure à celle des banques situées aux États-Unis et dans la zone euro. Enfin, le secteur bancaire canadien contribue davantage au niveau de risque au sein du système financier national que les institutions étrangères.

Classification JEL : C14, C58, G21, G32

Classification de la Banque : Stabilité financière; Réglementation et politiques relatives au système financier; Institutions financières; Méthodes économétriques et statistiques 


\section{Introduction}

Resilient, well-regulated financial systems are essential for economic and financial stability in a world of increased capital flows. Problems in financial systems can reduce the effectiveness of monetary policy and be extremely costly to the real economy, as illustrated in a number of financial crises in both industrial and developing economies in the past few decades, including the current global credit-liquidity turmoil. Therefore, supervisory authorities have devoted much effort to monitoring and regulating financial sector. It is a key issue in such supervision that policymakers need analytical tools to measure the systemic importance of individual institutions. In times of financial crisis, these tools can help them to gauge the likely impact of distress at a given financial institution on the stability of the overall banking system, while in normal times it is crucial to use such tools to calibrate prudential instruments, such as capital requirements and insurance premiums, according to the relative contribution of different institutions to systemic risk.

A few measures of systemic importance have been proposed in recent empirical studies. Adrian and Brunnermeier (2009) propose the conditional Value-at Risk (CoVaR) as a measure of systemic importance of financial institutions. Similar to the Value-at-Risk measure quantifying the unconditional tail risk of a financial institution, the CoVaR can capture how much the distress of one institution can increase the tail risk of others. This measure provides a clear way on the bilateral relation between the tail risks of two financial institutions. When applying CoVaR to measure the systemic importance of a financial institution to the entire system, we have to construct a system indicator on the status of the system, and then analyze the bilateral relation between the system indicator and a specific institution. However, the complexity of the financial system usually makes it difficult to construct a general indicator of the system. Furthermore, even if a system indicator is given, the CoVaR method is difficult to be generalized to measure a group of financial institutions's 
contribution to systemic risk.

Segoviano and Goodhart (2009) propose an indicator to measure the systemic importance of a specific institution by estimating the probability that one or more institutions in the system would be distressed given that this specific institution is distressed. This measure only considers the probability of the failure of at least another institution conditional on the failure of a specific institution, but it cannot provide further useful information on the systemic importance of institutions. For example, their measure cannot characterize the likelihood that all other institutions fall into failure given that a specific institution falls into failure. In addition, the estimation method of their measure is based on the minimum cross-entry approach (Kullback, 1959). Under this estimation approach, a posterior multivariate distribution is recovered using an optimization procedure by which a prior density function is required. Thus, the posterior density is constrained by the prior density which follows a parametric specification. A possible serious problem with such a parametric specification is model misspecification, which may lead to a misleading conclusion in inference and hypothesis testing.

Zhou (2010) proposes the systemic impact index to measure the expected number of bank failures in the banking system given one particular bank fails. Zhou's systemic impact index only focuses on how many banks are influenced when a particular bank fails, but it cannot provide sufficient information in identifying the systemic importance of a financial institution more than another. For example, even though two different institutions have the same value of systemic impact index, their contribution to systemic risk can be different.

In this paper, similarly as in Lehar (2005), systemic risk is defined as an event in which at least a certain fraction of financial institutions, for example, at least $r$ financial institutions, crash simultaneously. We measure the systemic importance of a financial institution or a group of finan- 
cial institutions by its contribution to the systemic risk. The higher the contribution is, the more systemic importance is the institution or the group of financial institutions. The contribution is defined as the difference between the conditional probability and unconditional probability of the simultaneous crashes of at least a certain fraction of financial institutions, where the conditional event in the conditional probability is the crash of this financial institution or this group of financial institutions. When $r$ taking values of $1,2, \ldots$, up to the number of all other financial institutions in the system, we obtain a set of different measures, each of which can capture different aspects of systemic importance of financial institutions. To see this more explicitly, we consider the following example. Two banks, $\mathrm{A}$ and $\mathrm{B}$, in a banking system with $m$ banks, report the same contribution to the crash of at least another institution (measure 1), but institution A gives more contribution to the simultaneous crashes of all other $m-1$ institutions (measure $m-1$ ). Thus, institution A is the same financial importance as institution $\mathrm{B}$ in terms of measure 1, but institution $\mathrm{A}$ is more systemically important than institution B in terms of measure $m-1$.

Given this set of measures on the systemic importance of financial institutions, two major practical application questions need to be addressed. First, how are these measures implemented? Second, is the data available? For the first question, we first show that each of these measures can be expressed as a summation of the joint tail probabilities. Then, we use multivariate extreme value techniques to estimate semi-parametrically the tail probabilities ${ }^{1}$. Note that our approach can allow us not only to measure the systemic importance of a financial institution, but also the impact that the failure of an institution would have on other institutions. For the second question, theoretically a bank is insolvent if the value of its liability exceeds the value of its assets. The major problem is that for important asset classes, in particular the loan portfolio, market prices are not available

\footnotetext{
${ }^{1}$ This estimation approach for extreme events has recently been used in the finance literature by Poon et.al (2004), Hartmann et al. (2005), Straetmans et al. (2008), and De Jonghe (2010).
} 
and thus it is not clear what the value of the assets is. Even if some balance sheet data, such as non-performing loan ratios, earnings and profitability, liquidity and capital adequacy ratios are available, these data typically have a relatively low-frequency (quarterly). Therefore, there have been growing efforts recently to measure the soundness of a financial system based on data from financial markets. For example, Elsinger and Lehar (2005), Hartmann (2005), Allenspach and Monin (2006), and others, propose to measure systemic risk, defined as the probability of a given number of simultaneous bank defaults, from equity return data. Similarly, Chan-Lau and Gravelle (2005), Avesani et al. (2006), and Segoviano and Goodhart (2009) use the default probability to measure the systemic risk by employing liquid equity market or credit default swap (CDS) market data. The market-based measures have two major advantages. First, they can be updated in a more timely fashion. Second, they are usually forward-looking, because asset price movements reflect changes in market anticipation on future performance of the underlying entities. In this paper, following some earlier studies in this literature, we propose to measure systemic importance of financial institutions based on stock prices of financial institutions. In particular, the systemic risk is defined as the simultaneous crashes of at least several institution stock prices, which are available at a daily frequency.

To highlight our approach, we apply our measures to identify systematically important banks in Canadian banking sector and major risk contributors from international financial institutions to Canadian banking sector. Using six big banks as the proxy for Canadian banking sector ${ }^{2}$, we find empirical evidence that (i) the systemic importance of the top three banks, RBC Financial Group, TD Bank Financial Group, and Scotiabank, is greater than other banks, although with different order in terms of different measures, but we also find empirical evidence that the size of

\footnotetext{
${ }^{2}$ The six largest banks in Canada by asset size (the big six banks) are: RBC Financial Group, TD Bank Financial Group, Scotiabank, the Bank of Montreal, CIBC, and National Bank. The big six banks account for more than 90 per cent of the assets in the Canadian Banking system.
} 
financial institution should not be considered as a proxy of systemic importance. For instance, the smaller bank, National bank, provides bigger risk contribution to the system than Bank of Montreal and Canadian Imperial Bank of Commerce; (ii) compared to the European and Asian banks, the crashes of U.S. banks, on average, are the most damaging to the Canadian bank sector, while the risk contribution to Canadian banking sector from Asian banks displays quite lower than that from banks in euro area and U.S.; (iii) risk contribution to Canadian banking sector exhibits "home bias ", that is cross-country risk contribution tends to be smaller than domestic risk contribution.

The remainder of this paper is organized as follows. Section 2 introduces our theoretical indicator of measuring systemic importance of financial institutions, and outlines the estimation procedures for the indicator. In section 3, the method is applied to measure the systemic importance of Canadian banks in Canadian banking sector and identify major risk contributors from international financial institutions to Canadian banking sector. Section 4 offers some conclusions. The mathematical proofs are presented in an appendix.

\section{Methodology}

In this section, we introduce a new approach to measure the systemic importance of financial institutions. This measure is constructed as the difference between the conditional probability and unconditional probability of the simultaneous crashes of at least several bank stock prices, where the conditional event is the crash of the financial institution stock price. The extreme value techniques are used to estimate the conditional and unconditional probabilities. 


\subsection{Systemic Importance Measures}

For notational simplicity, suppose that the financial system we are interested in is a banking system containing $m$ banks and let $X_{i}, i=1, \ldots, m$ respectively represent stock returns of the $m$ banks ${ }^{3}$, where $X_{i}$ denotes the log first difference of the price changes in bank stock. We adopt the convention to take the negative of stock returns, so that we can define all used formulae in terms of upper tail returns. A bank is assumed to be in crisis (crash, failure, or collapse) if its stock returns fall below a given crisis level at a given tail probability $p$. Thus, corresponding to the $m$ banks, there exist $m$ crisis levels denoted by $Q_{i}(p), i=1, \ldots, m$, such that

$$
P\left[X_{1}>Q_{1}(p)\right]=P\left[X_{2}>Q_{2}(p)\right] \ldots=P\left[X_{m}>Q_{m}(p)\right]=p
$$

With the significance level $p$ in common, the crisis levels $Q_{i}(p)$ generally differ across banks because the marginal distribution functions $P\left[X_{i}>Q_{i}(p)\right]=1-F_{i}\left(Q_{i}(p)\right)$ are bank specific.

We want to measure the systemic importance of a single bank or group of banks by measuring the increase in the systemic risk conditional on the crash of this bank or this group of banks. Thus we need to give the definition of the systemic risk. Similarly as Lehar (2005), we define the systemic risk as an event in which at least a certain fraction of banks (in this banking system) crash simultaneously. Given the definition, we first measure the systemic risk conditional on the crashes of a single bank or a group of banks by calculating the following probability of simultaneous collapses of at least $r$ banks conditional on the collapses of a subset banks,

$$
\begin{aligned}
P_{m-L \mid L}(r) & \equiv P\left[\exists i_{1}, i_{2}, \ldots, i_{r}, \bar{\in} S, \text { s.t. } X_{i_{l}}>Q_{i_{l}}(p), l=1, \ldots, r \mid \bigcap_{i \in S}\left(X_{i}>Q_{i}(p)\right)\right] \\
& =P\left[\bigcup_{i_{1}<i_{2}<\ldots<i_{r} l=1}^{r}\left(X_{i_{l}}>Q_{i_{l}}(p), i_{l} \bar{\in} S\right) \mid \bigcap_{i \in S}\left(X_{i}>Q_{i}(p)\right)\right],
\end{aligned}
$$

\footnotetext{
${ }^{3}$ There are other potential candidates, such as Credit Default Swap (CDS), can also be used to indicate the status of a bank. The choice of bank stock prices for measuring banking system risk may be motivated by Merton's (1974) option-theoretical framework toward default, which has become the cornerstone of a large body of approaches for quantifying credit risk and modeling credit rating migrations.
} 
where $S$ is the index set numbering individual banks and $L$ is the number contained in $S, \bigcap_{l=1}^{r}\left(X_{i_{l}}>\right.$ $\left.Q_{i_{l}}(p), i_{l} \bar{\in} S\right)$ is the event that $r$ banks (numbered by $i_{1}, i_{2}, \ldots$, and $i_{r}$ ) simultaneously crash, and $\bigcup_{i_{1}<i_{2}<\ldots<i_{r}} \bigcap_{l=1}^{r}\left(X_{i_{l}}>Q_{i_{l}}(p), i_{l} \bar{\in} S\right)$ is the event that at least $r$ banks crash, where $r$ is an integer and $1 \leq r \leq m-L$.

Let $N$ represent for the number of $r$ combinations out of $m-L$ banks. The contribution of the collapse of $L$ banks to the collapse of at least $r$ other banks is measured by

$$
\begin{aligned}
\triangle P_{m-L \mid L}(r) \equiv & P\left[\bigcup_{i_{1}<i_{2}<\ldots i_{r} l=1}^{r}\left(X_{i_{l}}>Q_{i_{l}}(p), i_{l} \bar{\in} S\right) \mid \bigcap_{i \in S}\left(X_{i}>Q_{i}(p)\right)\right] \\
& -P\left[\bigcup_{i_{1}<i_{2}<\ldots i_{r} l=1}^{r} \bigcap_{l=1}^{r}\left(X_{i_{l}}>Q_{i_{l}}(p), i_{l} \bar{\in} S\right)\right] .
\end{aligned}
$$

Clearly, the first term on the right hand side of the equation (3) characterizes the likelihood that conditional on the collapse of the $L$ banks in $S$, at least $r$ other banks in the system become crash, while the second term gives the unconditional probability of the collapses of at least $r$ other banks. Therefore, $\triangle P_{m-L \mid L}(r)$ captures the contribution of the failure of the $L$ banks to collapse of at least $r$ other banks. Consequently, for a given integer $r$, we propose $\triangle P_{m-L \mid L}(r)$ as a measure to identify the systemic importance of a specific bank or a group of banks if it becomes crash.

Equation (3) is very flexible in terms of the joint collapse set on the left hand side and conditional set on the right hand side in conditional probabilities, thereby presenting a set of measures of systemic importance of financial institutions based on relevant but different perspectives of measurements of systemic risk. For example, $\triangle P_{1 \mid 1}(1)$ can capture the increase in the risk of bank $i$ conditional on the crash of another bank $j$, therefore it can identify which banks are most at risk should a bank falls into crisis ${ }^{4} . \triangle P_{1 \mid 1}(1)$ is called as the extreme Corisk between two institutions. Two other particular examples are $\triangle P_{m-L \mid L}(1)$ and $\triangle P_{m-L \mid L}(m-L)$. Given that a group of banks

\footnotetext{
${ }^{4}$ From a financial stability and risk management perspective, it may be equally critical to assess the financial linkage at an institutional level.
} 
(a special case is $L=1$ ) becomes crashed, $\triangle P_{m-L \mid L}(1)$ measures the increase in the risk that at least one bank crashes, and $\triangle P_{m-L \mid L}(m-L)$ measures the increase in risk that all other $(m-L)$ banks crash.

It is important to note that the conditioning banks in above equations do not necessarily have to be a subset of the banking system. For example, a group of international banks can be chosen as the conditioning banks to explore the impact of foreign banks on the banking sector. Given the sharp increase in international banking activity in recent years (Chan-Lau et.al , 2007), such a tool can be used to identify the potential major financial institutions which influence the given banking system. Moreover, the conditioning random variables in above equations could also be others than just bank stock prices. For example, the conditional set can be limited to extreme downturns of the stock market index. It is also possible that the approach could be extended by including further economic variables or financial variables in the conditioning set, such as interest rates, exchange rates, financial stress index, and another indicator of aggregate risk. Using an aggregate random variable as a conditioning random variable, we can measure the extent that the banks are vulnerable to such a systemic risk.

Given the specification of a measure, a proper estimation of this measure is key importance for its implementation. The following theorem shows that $\triangle P_{m-L \mid L}(r)$ can be expressed as the summation of conditional and unconditional probabilities which can be estimated by extreme value theory approach.

Theorem 1 Let $N$ represent for the number of $r$ combinations out of $m-L$ banks, where $r$ is an integer and $1 \leq r \leq m-L$. Using $A_{1}^{(r)}, A_{2}^{(r)}, \ldots$, and $A_{N}^{(r)}$ to express all these combinations, the 
contribution of the collapse of $L$ banks to the collapse of at least $r$ other banks is measured by,

$$
\begin{aligned}
\triangle P_{m-L \mid L}(r) \equiv & P\left[\bigcup_{i_{1}<i_{2}<\ldots i_{r} l=1}^{r}\left(X_{i_{l}}>Q_{i_{l}}(p), i_{l} \bar{\in} S\right) \mid \bigcap_{i \in S}\left(X_{i}>Q_{i}(p)\right)\right] \\
& -P\left[\bigcup_{i_{1}<i_{2}<\ldots i_{r} l=1}^{r}\left(X_{i_{l}}>Q_{i_{l}}(p), i_{l} \bar{\in} S\right)\right] \\
= & S_{1}^{(r)}-S_{2}^{(r)}+\ldots+(-1)^{N} S_{N}^{(r)},
\end{aligned}
$$

where

$$
\begin{aligned}
S_{1}^{(r)} & =\sum_{1 \leq j \leq N}\left(P\left[A_{j}^{(r)} \mid \bigcap_{i \in S}\left(X_{i}>Q_{i}(p)\right)\right]-P\left[A_{j}^{(r)}\right]\right), \\
S_{2}^{(r)} & =\sum_{1 \leq i<j \leq N}\left(P\left[A_{i}^{(r)} \bigcap A_{j}^{(r)} \mid \bigcap_{i \in S}\left(X_{i}>Q_{i}(p)\right)\right]-P\left[A_{i}^{(r)} \bigcap A_{j}^{(r)}\right]\right), \\
& \vdots \\
S_{N}^{(r)} & =P\left(\bigcap_{i=1}^{N} A_{i}^{(r)} \mid \bigcap_{i \in S}\left(X_{i}>Q_{i}(p)\right)\right)-P\left(\bigcap_{i=1}^{N} A_{i}^{(r)}\right) .
\end{aligned}
$$

From Theorem $1, P_{m-L \mid L}(1)$ is measured by,

$$
\begin{aligned}
\triangle P_{m-L \mid L}(1) & =P\left[\bigcup_{j \in S}\left(X_{j}>Q_{j}(p)\right) \mid \bigcap_{i \in S}\left(X_{i}>Q_{i}(p)\right)\right]-P\left[\bigcup_{j \in S}\left(X_{j}>Q_{j}(p)\right)\right] \\
& =S_{1}^{(1)}-S_{2}^{(1)}+\ldots+(-1)^{m-L-1} S_{m-L}^{(1)},
\end{aligned}
$$

where

$$
\begin{aligned}
S_{1}^{(1)}= & \sum_{i \in \bar{S}}\left(P\left[\left(X_{i}>Q_{i}(p) \mid \bigcap_{i \in S}\left(X_{i}>Q_{i}(p)\right)\right)\right]-P\left[\left(X_{i}>Q_{i}(p)\right)\right]\right), \\
S_{2}^{(1)}= & \sum_{i<j, i, j \in \bar{\epsilon}}\left(P\left[\left(X_{i}>Q_{i}(p)\right) \bigcap\left(X_{j}>Q_{j}(p)\right) \mid \bigcap_{i \in S}\left(X_{i}>Q_{i}(p)\right)\right)\right] \\
& \left.-P\left[\left(X_{i}>Q_{i}(p)\right) \bigcap\left(X_{j}>Q_{j}(p)\right)\right]\right), \\
\vdots & \\
S_{m-L}^{(1)}= & \left.P\left[\bigcap_{i \bar{\epsilon} S}\left(X_{i}>Q_{i}(p)\right) \mid \bigcap_{i \in S}\left(X_{i}>Q_{i}(p)\right)\right)\right]-P\left[\bigcap_{i \bar{\in} S}\left(X_{i}>Q_{i}(p)\right)\right],
\end{aligned}
$$


and $\triangle P_{m-L \mid L}(m-L)$ is measured by,

$$
\triangle P_{m-L \mid L}(m-L)=P\left[\bigcap_{i \in \mathcal{E}}\left(X_{i}>Q_{i}(p)\right) \mid \bigcap_{i \in S}\left(X_{i}>Q_{i}(p)\right)\right]-P\left[\bigcap_{i \in S}\left(X_{i}>Q_{i}(p)\right)\right] .
$$

Equation (4) provides a practical guide for estimating the $\triangle P_{m-L \mid L}(r)$ by using multivariate extreme value techniques to estimate semiparametrically these conditional and unconditional probabilities on the right hand side of equation (see next section for details).

\subsection{Estimation Approach}

A key step to apply our approach to empirical investigation is to estimate these multivariate conditional and unconditional probabilities in equation (4). Within the framework of a parametric specification of the joint distribution function, the calculations of the multivariate probabilities in equation (4) are straightforward, because we can estimate the distributional parameters by parametric methods, for example, maximum likelihood techniques. However, since there is no evidence that all stock returns follow the same distribution, a serious problem with the parametric specification of a joint distribution is the model misspecification, which could lead to misleading results in inference and hypothesis testing. To avoid very specific assumptions of the distributions of the stock returns of banks and other aggregate financial variables, we use the semiparametric extreme value theory approach proposed by Ledford and Tawn (1996), and Poon et al.(2004) to estimate theses probabilities ${ }^{5}$. Extreme value theory is a tool used to consider the limiting distribution of the extreme values of a random variable instead of the distribution of this random variable. Under extreme value theory, even though fat tailed random variables may follow different distributions such as a stable Paretian or mixtures of normals, at the limit they all converge to the same underlying distribution. This indicates that for downside risk analysis there is no need for making

\footnotetext{
${ }^{5}$ This approach consists of generalizing the results from the generalized Pareto law behavior of the minima and maxima of the relevant distributions in univariate extreme value analysis to the bivariate case.
} 
assumptions as to the exact distributional form of this kind of data.

The joint probabilities in equation (4) are determined by the dependence among returns and their marginal distributions. In order to extract information on the tail dependence, we want to eliminate the impact of the different marginal distributions. Therefore, we transform the original returns series $X_{i}, i=1, \ldots, m$, to series with a common marginal distribution. After such a transformation, differences in joint tail probabilities across banking systems can be purely due to differences in the tail dependence structure of the extreme returns.

In terms of this spirit, we transform these bank stock returns to unit Pareto marginals,

$$
\tilde{X}_{i}=\frac{1}{1-F_{X_{i}}\left(X_{i}\right)}, i=1, \ldots, m
$$

where $F_{X_{i}}(\cdot)$ represents the marginal cumulative distribution function (cdf) for $X_{i}$. Replacing the unknown marginal cdfs with their empirical distribution functions, we have,

$$
\tilde{X}_{i}=\frac{n+1}{n+1-R_{X_{i}}}, i=1, \ldots, m
$$

where $n$ is the observation number of $X_{i}$ and $R_{X_{i}}$ is the rank order statistic of the return $X_{i}$. Any conditional probability in (4), for example, $P\left[\bigcap_{l=1}^{r}\left(X_{i_{l}}>Q_{i_{l}}(p)\right), i_{l} \bar{\in} S \mid \bigcap_{i \in S}\left(X_{i}>Q_{i}(p)\right)\right]$, can be written as,

$$
\begin{aligned}
& P\left[\bigcap_{l=1}^{r}\left(X_{i_{l}}>Q_{i_{l}}(p)\right), i_{l} \bar{\in} S \mid \bigcap_{i \in S}\left(X_{i}>Q_{i}(p)\right)\right] \\
= & \frac{P\left[\left(\bigcap_{l=1}^{r}\left(X_{i_{l}}>Q_{i_{l}}(p)\right), i_{l} \bar{\in} S\right) \bigcap\left(\bigcap_{i \in S}\left(X_{i}>Q_{i}(p)\right)\right)\right]}{P\left[\bigcap_{i \in S}\left(X_{i}>Q_{i}(p)\right)\right]} .
\end{aligned}
$$


Using the variable transform, we can rewrite the joint tail probability in (9) as follows,

$$
\begin{aligned}
& P\left[\left(\bigcap_{l=1}^{r}\left(X_{i_{l}}>Q_{i_{l}}(p)\right), i_{l} \bar{\in} S\right) \bigcap\left(\bigcap_{i \in S}\left(X_{i}>Q_{i}(p)\right)\right)\right] \\
= & P\left[\left(\bigcap_{l=1}^{r}\left(\tilde{X}_{i_{l}}>q\right), i_{l} \bar{\in} S\right) \bigcap\left(\bigcap_{i \in S}\left(\tilde{X}_{i}>q\right)\right)\right] \\
= & \left.P\left[\min _{\left(\min _{1 \leq l \leq r, i_{l}} \in S\right.}\left(\tilde{X}_{i_{l}}\right), \min _{i \in S}\left(\tilde{X}_{i}\right)\right)>q\right] \\
= & P\left[\min \left(Z_{1}, Z_{2}\right)>q\right],
\end{aligned}
$$

where $q=1 / p, Z_{1}=\min _{1 \leq l \leq r, i_{l} \in S}\left(\tilde{X}_{i_{l}}\right)$, and $Z_{2}=\min _{i \in S}\left(\tilde{X}_{i}\right)$. Hence, the transformation to unit Pareto marginals reduces the estimation of the multivariate probability to a univariate probability. The only assumption that has to be made is that the distribution of the minimum series $Z=\min \left(Z_{1}, Z_{2}\right)$ displays fat tails. Popular distribution models like the Student-t exhibits this tail behavior.

The univariate tail probability for a fat-tailed random variable, like the one in (10), can be estimated by using the semiparametric probability estimator from De Haan et al. (1994),

$$
\hat{P}[Z>q]=\frac{k}{n}\left(\frac{C_{n-k, n}}{q}\right)^{\alpha}
$$

where $\alpha>0$ is an unknown parameter and the tail cut-off point $C_{n-k, n}$ is the $(n-k)-$ th ascending order statistic from the cross-sectional minimum series such that $\lim _{n \rightarrow \infty}[1 / k(n)]=0$ and $k=$ $o(n)^{6}$.

The tail probability estimator is conditional upon the tail index $\alpha$ and a choice of the threshold parameter $k .^{7}$ This tail index $\alpha$ captures the tail probability's rate of decay in the probability.

\footnotetext{
${ }^{6}$ Other nonparametric methods, such as kernel methods, can also be used to estimate the univariate tail probability in (10)

${ }^{7}$ The estimator (10) basically extends the empirical distribution of $Z$ outside the domain of the sample by means of its asymptotic Pareto tail from $P[Z>q] \approx l(q) q^{-\alpha}, \alpha \geq 1$ with $q$ large and where $l(q)$ is a slowly varying function (i.e., $\lim _{q \rightarrow \infty} l(x q) / l(q)=1$ for all fixed $x>0$ ). An intuitive derivation of the estimator is provided in Danielesson and de Vries (1997).
} 
Clearly, the lower $\alpha$, the slower the probability decay and the higher the probability mass in the tail of $Z$.

To estimate $\alpha$ we use the popular Hill (1975) estimator for the index of regular variation $\eta$,

$$
\hat{\eta}=\frac{1}{k} \sum_{j=0}^{k-1} \ln \left(\frac{C_{n-j, n}}{C_{n-k, n}}\right)=\frac{1}{\hat{\alpha}},
$$

where $\hat{\eta}$ is the estimate of the parameter of tail dependence. A relatively high $\hat{\eta}$ corresponds with a relatively high dependence of the components $\left(\tilde{X}_{1}, \ldots, \tilde{X}_{m}\right)$. Further details on the Hill estimator can be found in Jansen and De Vries (1991). An important issue related to the dependence parameter $\eta$ is that it can used to examine interbank risk spillover between various groups of banks or different banking sectors, for example, between group of small size of banks and group of large size of banks, or Canadian and U.S. banking sectors ${ }^{8}$.

The choice of the threshold parameter $k$ is a point of concern in the extreme value theory literature. If $k$ is set too low, too few observations enter and determine the estimation. If one considers a large $k$, non-tail events may enter the estimation. Hence, if one includes too many observations, the variance of the estimate is reduced at the expense of a bias in the tail estimation. This results from including too many observations from the central range. With too few observations, the bias declines but the variance of the estimate becomes too large. A number of methods have been proposed to select $k$ in finite samples. Goldie and Smith (1987) suggest to select the parameter $k$ so as to minimize the asymptotic mean-squared error. In this paper, we use the heuristic procedure by the tail estimator as a function of $k$ and select $k$ in a region where $\hat{\eta}$ is stable. The study of the optimal choice of $k$ is beyond the scope of this paper and hence will be pursued in future research.

\footnotetext{
${ }^{8}$ Quintos, Fan and Phillips (2001) develop a number of tests for identifying single unknown breaks in the estimated in the tail index $\alpha(\eta)$. Their tests are used to assess whether breakpoints in asset return distributions exist for Asian stock markets. In addition, Hartmann et.al (2005) use these tests to assess various hypotheses regarding the evolution and structure of systemic risk in the banking system.
} 


\section{Empirical Findings}

The proposed methodology in Section 2 is general and can be applied to any financial system that consists of financial institutions with publicly tradeable equity, CDS contracts, or other publicly available data. For illustrative purposes, we apply these measures of systemic importance to the Canadian banking sector and analyze the extreme risk of Canadian banks from complementary perspectives by answering two main questions. First, at the level of an individual bank, we use $\triangle P_{1 \mid 1}(1)$ to measure the increase in risk of an individual bank when another bank falls into crash, which will help us to identify which banks are most at risk should a bank fall into crash. Second, we use $\triangle P_{m-L \mid L}(r)$ to measure the systemic importance of a specific bank or a group of banks if they become crashed. In addition, we also explore the impact of the crashes of major foreign banks on Canadian banks, and measure the relative importance of the risk of domestic spillovers between banks as compared to the risk of cross-border spillovers.

\subsection{Data and Descriptive Statistics}

The data we use in this empirical work are daily stock price for publicly traded financial institutions. Canadian financial institutions considered consist of six big banks, namely RBC Financial Group (RBC), TD Bank Financial Group(TD), Scotiabank (BNS), Bank of Montreal (BMO), CIBC, and National Bank (NB); three insurance companies, Sunlife Financial Inc (SLIFE), Great West Life (GW) and Manulife Financial Canada; two other small banks, Laurentian Bank of Canada (LAU), Canadian Western Bank (CW). They represent Canadian biggest commercial banks and nonbank institutions in Canada and therefore have a direct and major impact on the Canadian financial institutions. In addition to Canadian financial system, we also consider the impacts of major international financial institutions on Canadian financial institutions. The group of 
major international banks considered consists of ten U.S. banks: Jp Morgan Chase (JpMorgan), Citigroup (CITIG), Bank of American (BOA), Wells Fargo and Company (FARGO), Goldman Sachs (GOLDMAN), American International Group (AIG), Morgan Stanley (MS), US Bancop (BANCORP), Bank of New York (BNYORK), and State Street (SSTREET); ten European banks: Deutsche Bank (DEUTSCHE), Barclay Plc (BARCLAY), BNP Paribas (BNPPAR), HSBC, UBS, Societe General (SOCIETE), Banco Santander(BANCO), Credit Agricole (CA), Commerzbank (COMMERZ), and Creditswiss(CS); and three Asian banks: Mitsubishi UFJ (MITSUB), Mizuho Finl (MIZUHO), and Sumitomo Corp (SUMIT). The stock market risk factors or aggregate shocks are proxied by TSX (Canadian stock market index) for Canada, Sp500 (The U.S. stock market index) for U.S. , E100 (The European 100 stock index) for European area, and NIKKEI 225 (Japan stock market index) for Japan. Both the stock returns and market index returns are constructed by taking log first differences of stock price and stock market indices, respectfully. All series, except for GOLDMAN, start on 3 January 1994 and end on 21 September 2009, rendering 4101 return observations.

Table 1 presents the descriptive statistics for institution stock return series and four market stock index returns. Mean returns are basically zero, as one would expect for high data frequencies. Compared to the standard deviations of U.S., European, and Asian institution stock returns, Canadian institution stock returns exhibit the lowest standard deviations. All time series exhibit high excess kurtosis, which provides evidence that these series are leptokurtic and have heavy tails. This indicates that our heavy-tail assumption on the tail of losses is valid for the data. Table 1 also reveals that the Jarque-Bera statistics strongly reject the null hypothesis of normal distribution at any critical values commonly used. The results of formal augmented Dickey-Fuller non-stationary tests indicate that the null hypothesis of non-stationarity is rejected at the $5 \%$ significant level. 


\subsection{Extreme Co-Risk between Individual Institutions}

Our measures of the contribution of a particular institution or a specific group of institutions to another institution or the overall systemic risk is based on the co-movements among institutions, and capture both idiosyncratic effects as well as exposure among all institutions to common factors, e.g., the Canadian stock market, the U.S. stock market, etc. To remove the effects from commonfactor exposure, we use the following formulae to measure the contribution to the crash probability of an institution conditional on the failure of another institution $\left(\triangle P_{1 \mid 1}(1)\right)$,

$$
\begin{aligned}
\triangle P_{1 \mid 1}(1)= & \left\{P\left[X_{1}>Q_{1}(p) \mid X_{2}>Q_{2}(p), Y_{1}>Q_{Y_{1}}(p), Y_{2}>Q_{Y_{2}}(p)\right]-P\left[X_{1}>Q_{1}(p)\right]\right\} \\
& -\left\{P\left[X_{1}>Q_{1}(p) \mid Y_{1}>Q_{Y_{1}}(p), Y_{2}>Q_{Y_{2}}(p)\right]-P\left[X_{1}>Q_{1}(p)\right]\right\},
\end{aligned}
$$

where $Y_{1}$ and $Y_{2}$ in equation (13) stand for the index returns of the stock markets, and they are chosen as follows: TSX and Sp500 for the extreme Corisk between Canadian and U.S. institutions, TSX and NIKKEI 225 between Canadian and Japanese institutions, and TSX and E100 for Canadian and European institutions. The first part $P\left[X_{1}>Q_{1}(p) \mid X_{2}>Q_{2}(p), Y_{1}>Q_{Y_{1}}(p) Y_{2}>\right.$ $\left.Q_{Y_{2}}(p)\right]-P\left[X_{1}>Q_{1}(p)\right]$ in equation (13) measures the contribution of institution 2, common factors $Y_{1}$, and $Y_{2}$, to the crash of the institution 1, while the second part $P\left[X_{1}>Q_{1}(p) \mid Y_{1}>\right.$ $\left.Q_{Y_{1}}(p), Y_{2}>Q_{Y_{2}}(p)\right]-P\left[X_{1}>Q_{1}(p)\right]$ measures only the contribution from the two common factors. Thus, the difference $\left(\triangle P_{1 \mid 1}(1)\right)$ between the first part and second part removes the influences from the two common factors, and captures the contribution from idiosyncratic shocks of institution 2 to institution 1. Similarly, for any integer $0 \leq r \leq m-L$, the following formulae is used to 
measure the systemic importance of an institution or group of institutions,

$$
\begin{aligned}
\triangle P_{m-L \mid L}(r)= & \left\{P\left[\bigcup_{i_{1}<i_{2}<\ldots i_{r} l=1}^{r}\left(X_{i_{l}}>Q_{i_{l}}(p), i_{l} \in \bar{\in} S\right) \mid \bigcap_{i \in S}\left(X_{i}>Q_{i}(p), Y_{1}>Q_{Y_{1}}(p), Y_{2}>Q_{Y_{2}}(p)\right)\right]\right. \\
& \left.-P\left[\bigcup_{i_{1}<i_{2}<\ldots i_{r} l=1}^{r}\left(X_{i_{l}}>Q_{i_{l}}(p), \bar{\epsilon} S\right)\right]\right\} \\
& -\left\{P\left[\bigcup_{i_{1}<i_{2}<\ldots i_{r} l=1}^{r}\left(X_{i_{l}}>Q_{i_{l}}(p), i_{l} \bar{\in} S\right) \mid\left(Y_{1}>Q_{Y_{1}}(p), Y_{2}>Q_{Y_{2}}(p)\right)\right]\right. \\
& \left.-P\left[\bigcup_{i_{1}<i_{2}<\ldots i_{r} l=1}^{r}\left(X_{i_{l}}>Q_{i_{l}}(p), \bar{\epsilon} S\right)\right]\right\} .
\end{aligned}
$$

Table 2 reports the increase in the crash probability of the institution specified in the column when another institution in the row becomes crashed. For example, the value $23.5 \%$ in the column "RBC" and the row "TD" indicates that the crash probability of RBC increases $23.5 \%$ when TD is experiencing a crisis, and all values of $\triangle P_{1 \mid 1}(1)$ in the row "TD" capture the increase in the crash probability of any other institutions associated with the crash of TD. Among the Canadian financial institutions in the analysis, BNS is the most exposed to the risk associated with the crashes of other institutions, with its average Corisk reaching $27.1 \%$ (the average of the column "BNS" ) followed by BMO with $24.6 \%$ (the average of column BMO), CIBC with $24 \%$ (the average of column CIBC), RBC with 23.9\%, MLIFE with 23.8\%, and TD with $22.8 \%$. In turn, BNS, RBC, TD, BMO, and MLIFE are the top five largest contributors to the systemic risk with their average Corisk values at $24.2 \%$ (the average of row BNS), $23.2 \%, 21.5 \%, 21.3 \%$, and $21.1 \%$, respectively. On one hand, this result suggests that BNS, RBC and TD are systematically important banks in term of their contributions to the system risk, but on the other hand BNS, BMO, and CIBC are most exposed to the risk from the crashes of other institutions, which indicates RBC and TD contribute more risk to the system than BMO and CIBC, but they suffer less risk effects from other institutions than BMO and CIBC. Table 2 displays that on average, Lau is less affected by other financial institutions, while it contributes the lowest risk to the financial system. 
Table 2 shows that the maximum Corisk value occurs between Canadian institutions, which indicates that the major spillover risk to Canadian institutions comes from domestic institutions rather than foreign institutions. For example, when going through values in column RBC, we find that the maximum Corisk value is $33.1 \%$ describing the Corisk between BNS and RBC, which is larger than any Corisk value between RBC and any foreign institutions. Actually, when going through all the columns in table 2, it turns out that the highest Corisk value occurs between Canadian institutions. This result provides the evidence of the existence of "home bias" in spillover risk, i.e., cross-country risk spillover tends to be smaller than domestic risk spillover. Another important observation form table 2 is that on average, if any of the Canadian institutions fall into crashes, the average of Corisk values of the other Canadian institutions being crashed is $21.1 \%$, while the averages of the Corisk values of Canadian institutions conditional on the crashes of the institutions in U.S., Europe, and Asia are 15.4\%,8.9\%, and 5.3\%, respectively. These findings not only suggest that the highest Corisk value exists between Canadian institutions, but also indicates that on average, compared to the institutions in the U.S., Europe, and Asia, the crashes of Canadian institutions are the most damaging to the domestic institutions.

It is important to note that SLIFE benefits from the failure of SUMIT (negative Corisk). The potential explanation for this phenomenon is "flight to quality", or "competive effects", which suggests that some banks benefit from the troubles at other banks, as (e.g.) depositors withdraw their funds from the bad banks to put them in good banks. Such behavior has been refereed by Kaufman (1988) in relation to U.S. banking history, and Saunders and Wilson (1996) provided some evidence for it during two years of the Great Depression.

On average, Wells Fargo, Jpmorgan, and BOA represent three biggest international risk banks for Canadian institutions. Among European institutions, BBVA, UBS, and DEUTS are the three 
biggest risk banks for Canadian institutions. Compared with institutions in both the U.S. and Europe, shocks to Japanese institutions display quite lower impact on Canadian institutions.

\subsection{Measuring Systemic Importance of Canadian Banks}

Based on the Corisk measure between institutions, we use the average of Corisk between institutions to measure the increase in the risk of Canadian financial system conditional on the crash of a specific institution, but it is obvious that the joint crash of financial system may experience a nonlinear relationship rather than the average Corisk between individual institutions. Consequently, from different perspectives by taking different values of $L, m$ and $r$, we use $\triangle P_{m-L \mid L}(r)$ to quantify and identify the systemic importance of institutions.

When $r=10, L=1$, and $m-L=10$, Figure 1 reports the increase in the risk that all other institutions become crashed when a specific institution falls into crash $\left(\triangle P_{10 \mid 1}(10)\right)$. For comparison, the average of the extreme Corisks between this specific institution and all other institutions (average of all $\triangle P_{10 \mid 1}(10)$ between this institution and all other institution) is also reported in Figure 1. It is noticeable that RBC, TD, and BNS again are the top three highest values of $\triangle P_{10 \mid 1}(10)$ with $8.3 \%, 8.1 \%$, and $7.2 \%$, respectively, even though these values are very close to each other. The MLIFE reports the fourth highest value of $\triangle P_{10 \mid 1}(10)$ at $7 \%$ followed by BMO with $6.8 \%$, which indicating that the top-five institutions are ordered by RBC, TD, BNS, MLIFE, and BMO in terms of the measure $\triangle P_{10 \mid 1}(10)$. MLIFE has a higher value of $\triangle P_{10 \mid 1}(10)$ than $\mathrm{BMO}, \mathrm{CIBC}$, and NB, which suggests that the size of a financial institution should not be considered as a proxy of systemic importance ${ }^{9}$. Figure 1 also shows that for every institution, $\triangle P_{10 \mid 1}(10)$ is consistently

\footnotetext{
${ }^{9}$ Based on daily stock returns of 28 U.S. banks, Zhou (2010)provides empirical evidence that the size measures are not good proxy of the systemic importance. Therefore, size should not be automatically regarded as a proxy of systemic importance. Tarashev et.al (2009) consider financial systems that possess the following three features. First, all banks in a given system share the same probability default and exposure to the common factor. Second, there are three big banks of equal size, which account for $40 \%$ of the overall system. Third, a group of equally-sized small banks make up the rest of the system. In all of these systems, the systemic importance of a big bank is greater than
} 
smaller than the average of the extreme Corisk. A possible explanation for this result is that a simple average repeatedly adds up the interactions among individual institutions which could be higher than the actual risk of joint crash.

To further explore the systemic importance of Canadian financial institutions from different perspectives, Figure 2 reports the estimations of $\triangle P_{10 \mid 1}(r)$, for $r=1,2$, and 3 , which measure the increase in the risk from the simultaneous collapse of at least $r(r=1,2,3)$ financial institutions conditional on the collapse of a specific institution. To name a few with the highest values of $\triangle P_{10 \mid 1}(1), \triangle P_{10 \mid 1}(2)$, and $\triangle P_{10 \mid 1}(3)$, BNS has the highest $\triangle P_{10 \mid 1}(1)$ followed by RBC, BMO, TD, and MLIFE; BNS reports the highest $\triangle P_{10 \mid 1}(2)$ followed by RBC, MLIFE, BMO, and TD. The five highest $\triangle P_{10 \mid 1}(3)$ institutions are ordered as TD, RBC, BNS, MLIFE, and BMO which are the same institutions as those with highest values of $\triangle P_{10 \mid 1}(1)$ and $\triangle P_{10 \mid 1}(2)$, even though there is a different order. Overall, from Figures 1 and 2, we find that the five financial institutions, RBC, TD, BNS, BMO, and MLIFE have consistently higher values of $\triangle P_{10 \mid 1}(1), \triangle P_{10 \mid 1}(2)$, and $\triangle P_{10 \mid 1}(3)$ than other institutions, suggesting that the five financial institutions are more systemically important than other financial institutions in terms of the measures $\triangle P_{10 \mid 1}(1), \triangle P_{10 \mid 1}(2)$, and $\triangle P_{10 \mid 1}(3)$. Notably, Figure 2 displays that SunLife is more systemically important than GW, Lau, and $\mathrm{CW}$, although it is less important than the top five financial institutions.

We remove the three non-bank financial institutions (GW, SLIFE, and MLIFE) from the list of Canadian financial institutions and use six big banks as a proxy for the Canadian banking sector to focus on identifying and quantifying the systemic importance of each bank in the six big banks. However, we still use the three non-bank financial institutions to examine how the risks from nonbank financial institutions are related to the Canadian banking sector, while choosing the two small banks (Lau, CW ) as proxy for other Canadian banks to investigate how important other Canadian that of a small one. 
banks are for the Canadian banking sector. In addition, we take the world's major institutions in the United States, European countries, and Asia to estimate the cross-country risk impacts on Canadian banking sector.

To measure the systemic importance of each bank in the six big banks when this bank is excluded from this six big banks, we consider six groups of banks respectfully denoted by $A_{1}=\{\mathrm{TD}$, BNS, BMO, CIBC, NB $\}, A_{2}=\{\mathrm{RBC}, \mathrm{BNS}, \mathrm{BMO}, \mathrm{CIBC}, \mathrm{NB}\}, A_{3}=\{\mathrm{RBC}, \mathrm{TD}, \mathrm{BMO}, \mathrm{CIBC}, \mathrm{NB}\}$, $A_{4}=\{\mathrm{RBC}, \mathrm{TD}, \mathrm{BNS}, \mathrm{CIBC}, \mathrm{NB}\}, A_{5}=\{\mathrm{RBC}, \mathrm{TD}, \mathrm{BNS}, \mathrm{BMO}, \mathrm{NB}\}$, and $A_{6}=\{\mathrm{RBC}, \mathrm{TD}, \mathrm{BNS}$, $\mathrm{BMO}, \mathrm{CIBC}\}$.

The estimations of the five systemic importance measures, $\triangle P_{5 \mid 1}(r), r=1,2, \ldots, 5$, are reported in tables 3-7, respectively. We start with the $\triangle P_{5 \mid 1}(1)$ measure which reports in table 3 the increase in the crash probability that at least one bank in each group in the column become crashed when the bank in the row becomes crashed. For example, the value $30.6 \%$ in the row "RBC" and the column " $A_{1}$ " in panel a refers to the increase in the probability that the group of banks $A_{1}$ falls into failure if $\mathrm{RBC}$ is experiencing a crash. The banks in ascending order of the $\triangle P_{5 \mid 1}(1)$ values are $\mathrm{BNS}, \mathrm{RBC}$, TD, $\mathrm{BMO}, \mathrm{NB}$, and $\mathrm{CIBC}$, with their respective $\triangle P_{5 \mid 1}(1)$ values being $32.4 \%, 30.6 \%, 29.6 \%, 29.4 \%, 27 \%$, and $26.7 \%$. In table 4 , the top three values of $\triangle P_{10 \mid 1}(2)$ are ordered as BNS, RBC, and TD, which are the same order as those with the highest values of $\triangle P_{10 \mid 1}(1)$ in table 3, although the three lowest $\triangle P_{5 \mid 1}(2)$ banks have different order from that of three lowest $\triangle P_{5 \mid 1}(1)$ banks.

The values of $\triangle P_{5 \mid 1}(3), \triangle P_{5 \mid 1}(4)$, and $\triangle P_{5 \mid 1}(5)$ give a somewhat different outlook of the order of their top three banks compared to the measures of $\triangle P_{5 \mid 1}(1)$ and $\triangle P_{5 \mid 1}(2)$, but they report the same top three banks as $\triangle P_{5 \mid 1}(1)$ and $\triangle P_{5 \mid 1}(2)$, although with a different order, that is the top three banks are always RBC, TD, and BNS across the five different measures, although their order 
could be different. Notably, tables 3-7 suggest that the two lowest values of all the five measures come from CIBC and NB. The lowest values of $\triangle P_{10 \mid 1}(2), \triangle P_{10 \mid 1}(3)$, and $\triangle P_{10 \mid 1}(4)$ come from $\mathrm{NB}$, while the bank CIBC has the lowest values of $\triangle P_{10 \mid 1}(1)$ and $\triangle P_{10 \mid 1}(5)$, which indicates that the two lowest values of the five measures comes from CIBC and NB. As noted that for $\triangle P_{10 \mid 1}(1), \triangle P_{10 \mid 1}(2)$, and $\triangle P_{10 \mid 1}(3)$, even though $\mathrm{RBC}$ has a higher size than BNS in terms of total assets, it is less systemic importance than BNS in terms of the measures $\triangle P_{10 \mid 1}(r), r=1,2,3$, suggesting that the size measures are not good proxy of the systemic importance. Therefore, size should not be automatically regarded as a proxy of systemic importance.

To summarize, by applying the five proposed measures on systemic importance to the artificially constructed Canadian banking system consisting of big six Canadian banks, we find that the systemic importance of RBC, TD and BNS is greater than other banks, even though the three banks have different order for each measure. The empirical results based on the five measures provide evidence that the "too big to fail" argument (larger banks exhibits higher systemic importance) is not always valid, suggesting that the size of a bank should not be considered as a proxy of its systemic importance without careful justification based on systemic importance measures.

To explore the potential risk factors to Canadian banking sector from global major banks, we use the proposed systemic importance measures to assess the impact of the global major institutions on the Canadian banking sector. The tables 3-7 also report the values of $\triangle P_{5 \mid 1}(r)(r=1, \ldots, 5)$ between Canadian banking sector and major global institutions. The empirical findings reveal several other key trends. We find that "home bias" is a dominant factor in terms of the contribution to the increase in the risk of Canadian banking system. For example, in tables 3-6, going through each column from $A_{1}$ to $A_{5}$, it reveals that the highest value of each $\triangle P_{5 \mid 1}(r)(r=1,2, \ldots, 5)$ comes from one of the five big banks (RBC, TD, BNS, BMO, and CIBC), and the last column in table 7 
indicates that GW has the highest value of $\triangle P_{5 \mid 1}(5)$, suggesting that the Canadian banking sector is the most vulnerable to the risk from domestic financial institutions rather than foreign institutions. The "home bias" effects are also shown by Figure 3 where NB has more contribution to the crash probabilities of the five biggest Canadian banks than major international banks ${ }^{10}$.

On average, compared to the Canadian small banks, and the institutions in the U.S., Euro, and Asia, the three Canadian non-bank financial institutions have higher risk contribution to the Canadian banking system. However, on a country-by-country basis, the U.S.'s institutions consistently represent the biggest risk factor for the Canadian banking system. Specifically, Wells and BOA are consistently the top two risk contributors to the Canadian banking system among all foreign institutions considered in this paper. On average, among the European banks, the Canadian banking system are most exposed to the risk from the three banks, BBVA, DEUTS, and UBS AG.

\section{Conclusion}

This paper proposes a set of tools to measure the systemic importance of financial institutions. We measure the systemic importance of a financial institution or a group of financial institutions by its contribution to the systemic risk. The higher the contribution is, the more systemically important is the institution or the group of financial institutions. The contribution is defined as the difference between the conditional probability and unconditional probability of the simultaneous crashes of at leats of a certain fraction of financial institutions, where the conditional event in the conditional probability is the crash of this financial institution or this group of financial institutions. Given these measures, we propose an approach to estimate these measures by expressing these measures as a summation of conditional and unconditional probabilities of crashes. Then we use multivariate

\footnotetext{
${ }^{10}$ Figure 4 shows the contribution of each of Canadian six big banks to the crashes of at least $r$ banks of the U.S. five big banks, where $r=1,2$, 3. Figures 3 and 4 indicate that U.S. banks have stronger impacts on Canadian banks than Canadian banks on U.S. banks.
} 
extreme value theory to estimate semiparametrically these probabilities.

To highlight our approach, we apply our measures to identify the systemic importance of Canadian banking sector and major risk contributors from international financial institutions to Canadian banking sector. Using six big banks as the proxy for the Canadian banking sector. We find the empirical evidences that the systemic importance of the top three banks, RBC, TD, and BNS is greater than other banks. We also find that empirical evidence that the size of a financial institution should not be considered as a proxy of systemic importance. Compared to the European and major Asian institutions, the crashes of the U.S. institutions, on average, are the most damaging to the Canadian bank sector, while the risk contribution to Canadian banking sector from Asian banks display quite lower than that from institutions in euro area and U.S.. The risk contribution to Canadian banking sector exhibits "home bias", that is cross-country risk contribution tends to be smaller than domestic risk contribution. 


\section{Appendix}

Proof of Theorem 1. We use mathematical induction to prove theorem 1. For $r=1$, we use $\left(X_{i_{l}}>Q_{i_{l}}(p)\right), l \bar{\in} S$ to represent that the bank $i_{l}$ which is not in $S$ is in crisis. Then, the event that at least one extra bank is in crisis can be written as $\bigcup_{l \bar{E} S}\left(X_{i_{l}}>Q_{i_{l}}\right)$. Let $n=m-L$ express the number of banks contained in $\bar{S}$, where $\bar{S}$ is the complementary of $S$. When $n=1, \triangle P_{m-L \mid L}(1)=$ $P\left[\left(X_{i_{1}}>Q_{i_{1}}(p), i_{1} \bar{\in} S\right) \mid \bigcap_{i \in S}\left(X_{i}>Q_{i}(p)\right)\right]-P\left[\left(X_{i_{1}}>Q_{i_{1}}(p), i_{1} \bar{\in} S\right)\right]$, so equation (4) holds. For the simplicity of notation, we use $\left(X_{i l}>Q_{i_{l}}(p)\right)$ replace $\left(X_{i l}>Q_{i_{l}}(p), i_{l} \bar{\in} S\right)$. For $n=2$, we have

$$
\begin{aligned}
\triangle P_{m \mid L}(1) \equiv & P\left[\left(X_{i_{1}}>Q_{i_{1}}(p)\right) \bigcup\left(X_{i_{2}}>Q_{i_{2}}(p)\right) \mid \bigcap_{i \in S}\left(X_{i}>Q_{i}(p)\right)\right] \\
& -P\left[\left(X_{i_{1}}>Q_{i_{1}}(p)\right) \bigcup\left(X_{i_{2}}>Q_{i_{2}}(p)\right)\right] \\
= & P\left[\left(X_{i_{1}}>Q_{i_{1}}(p)\right) \mid \bigcap_{i \in S}\left(X_{i}>Q_{i}(p)\right)\right]-P\left[\left(X_{i_{1}}>Q_{i_{1}}(p)\right)\right] \\
& +P\left[\left(X_{i_{2}}>Q_{i_{2}}(p)\right) \mid \bigcap_{i \in S}\left(X_{i}>Q_{i}(p)\right)\right]-P\left[\left(X_{i_{2}}>Q_{i_{2}}(p)\right)\right] \\
& -P\left[\left(X_{i_{1}}>Q_{i_{1}}(p)\right) \bigcap\left(X_{i_{2}}>Q_{i_{2}}(p)\right) \mid \bigcap_{i \in S}\left(X_{i}>Q_{i}(p)\right)\right] \\
& +P\left[\left(X_{i_{1}}>Q_{i_{1}}(p)\right) \bigcap\left(X_{i_{2}}>Q_{i_{2}}(p)\right)\right] \\
\equiv & S_{1}^{(1)}-S_{2}^{(1)}
\end{aligned}
$$

where

$$
\begin{aligned}
S_{1}^{(1)}= & P\left[\left(X_{i_{1}}>Q_{i_{1}}(p)\right) \mid \bigcap_{i \in S}\left(X_{i}>Q_{i}(p)\right)\right]-P\left[\left(X_{i_{1}}>Q_{i_{1}}(p)\right)\right] \\
& +P\left[\left(X_{i_{2}}>Q_{i_{2}}(p)\right) \mid \bigcap_{i \in S}\left(X_{i}>Q_{i}(p)\right)\right]-P\left[\left(X_{i_{2}}>Q_{i_{2}}(p)\right)\right] \\
S_{2}^{(1)}= & P\left[\left(X_{i_{1}}>Q_{i_{1}}(p)\right) \bigcap\left(X_{i_{2}}>Q_{i_{2}}(p)\right) \mid \bigcap_{i \in S}\left(X_{i}>Q_{i}(p)\right)\right] \\
& -P\left[\left(X_{i_{1}}>Q_{i_{1}}(p)\right) \bigcap\left(X_{i_{2}}>Q_{i_{2}}(p)\right)\right],
\end{aligned}
$$

which indicates that equation (4) holds for $n=2$. Assuming that equation (4) holds for $n=k$, we 
want to prove that equation (4) holds for $n=k+1$. We have

$$
\begin{aligned}
& \triangle P_{m \mid L}(1) \equiv P\left[\bigcup_{l=1}^{k+1}\left(X_{j_{l}}>Q_{j}(p)\right) \mid \bigcap_{i \in S}\left(X_{i}>Q_{i}(p)\right)\right]-P\left[\bigcup_{l=1}^{k+1}\left(X_{j_{l}}>Q_{j}(p)\right)\right] \\
& =P\left[\left(\bigcup_{l=1}^{k}\left(X_{j_{l}}>Q_{j}(p)\right)\right) \bigcup\left(X_{j_{k+1}}>Q_{j_{k+1}}(p)\right) \mid \bigcap_{i \in S}\left(X_{i}>Q_{i}(p)\right)\right] \\
& \left.-P\left[\left(\bigcup_{l=1}^{k}\left(X_{j_{l}}>Q_{j}(p)\right)\right) \bigcup\left(X_{j_{k+1}}>Q_{j}(p)\right)\right)\right] \\
& =P\left[\left(\bigcup_{l=1}^{k}\left(X_{j_{l}}>Q_{j}(p)\right)\right) \mid \bigcap_{i \in S}\left(X_{i}>Q_{i}(p)\right)\right]-P\left[\left(\bigcup_{l=1}^{k}\left(X_{j_{l}}>Q_{j}(p)\right)\right)\right] \\
& +P\left[\left(X_{j_{k+1}}>Q_{j_{k+1}}(p)\right) \mid \bigcap_{i \in S}\left(X_{i}>Q_{i}(p)\right)\right]-P\left[\left(X_{j_{k+1}}>Q_{j_{k+1}}(p)\right)\right] \\
& -P\left[\bigcup_{l=1}^{k}\left\{\left(X_{j_{l}}>Q_{j}(p)\right) \bigcap\left(X_{j_{k+1}}>Q_{j_{k+1}}(p)\right)\right\} \mid \bigcap_{i \in S}\left(X_{i}>Q_{i}(p)\right)\right] \\
& +P\left[\bigcup_{l=1}^{k}\left\{\left(X_{j_{l}}>Q_{j}(p)\right) \bigcap\left(X_{j_{k+1}}>Q_{j_{k+1}}(p)\right)\right\}\right] \\
& =S_{1}^{(1)^{\prime}}-S_{2}^{(1)^{\prime}}+\ldots+(-)^{k} S_{k}^{(1)^{\prime}} \\
& +P\left[\left(X_{j_{k+1}}>Q_{j_{k+1}}(p)\right) \mid \bigcap_{i \in S}\left(X_{i}>Q_{i}(p)\right)\right]-P\left[\left(X_{j_{k+1}}>Q_{j_{k+1}}(p)\right)\right] \\
& -P\left[\bigcup_{l=1}^{k}\left\{\left(X_{j_{l}}>Q_{j}(p)\right) \bigcap\left(X_{j_{k+1}}>Q_{j_{k+1}}(p)\right)\right\} \mid \bigcap_{i \in S}\left(X_{i}>Q_{i}(p)\right)\right] \\
& +P\left[\bigcup_{l=1}^{k}\left\{\left(X_{j_{l}}>Q_{j}(p)\right) \bigcap\left(X_{j_{k+1}}>Q_{j_{k+1}}(p)\right)\right\}\right] .
\end{aligned}
$$

Using the assumption that $n=k$, we have,

$$
\begin{aligned}
& P\left[\bigcup_{l=1}^{k}\left\{\left(X_{j_{l}}>Q_{j}(p)\right) \bigcap\left(X_{j_{k+1}}>Q_{j_{k+1}}(p)\right)\right\} \mid \bigcap_{i \in S}\left(X_{i}>Q_{i}(p)\right)\right] \\
& -P\left[\bigcup_{l=1}^{k}\left\{\left(X_{j_{l}}>Q_{j}(p)\right) \bigcap\left(X_{j_{k+1}}>Q_{j_{k+1}}(p)\right)\right\}\right] \\
= & S_{1}^{(1)^{\prime \prime}}-S_{2}^{(1)^{\prime \prime}}+\ldots+(-)^{k} S_{k}^{\left(1^{\prime \prime}\right)}
\end{aligned}
$$


where

$$
\begin{aligned}
S_{1}^{(1)^{\prime \prime}=} & \sum_{l=1}^{k}\left(P\left[\left\{\left(X_{j_{l}}>Q_{j}(p)\right) \bigcap\left(X_{j_{k+1}}>Q_{j_{k+1}}(p)\right)\right\} \mid \bigcap_{i \in S}\left(X_{i}>Q_{i}(p)\right)\right]\right. \\
& \left.-P\left[\left\{\left(X_{j_{l}}>Q_{j}(p)\right) \bigcap\left(X_{j_{k+1}}>Q_{j_{k+1}}(p)\right)\right\}\right]\right), \\
\vdots & \\
S_{k}^{(1)^{\prime \prime}=} & P\left[\bigcap_{l=1}^{k}\left\{\left(X_{j_{l}}>Q_{j}(p)\right) \bigcap\left(X_{j_{k+1}}>Q_{j_{k+1}}(p)\right)\right\} \mid \bigcap_{i \in S}\left(X_{i}>Q_{i}(p)\right)\right] \\
& -P\left[\bigcap_{l=1}^{k}\left\{\left(X_{j_{l}}>Q_{j}(p)\right) \bigcap\left(X_{j_{k+1}}>Q_{j_{k+1}}(p)\right)\right\}\right] .
\end{aligned}
$$

Putting $(A .2)$ into $(A .1)$, and let $S_{1}^{(1)}=S_{1}^{(1)^{\prime}}+P\left[\left(X_{j_{k+1}}>Q_{j_{k+1}}(p)\right) \mid \bigcap_{i \in S}\left(X_{i}>Q_{i}(p)\right)\right]-P\left[\left(X_{j_{k+1}}>\right.\right.$ $\left.\left.Q_{j_{k+1}}(p)\right)\right], S_{2}^{(1)}=S_{2}^{(1)^{\prime}}+S_{1}^{(1)^{\prime \prime}}, \ldots, S_{k}^{(1)}=S_{k}^{(1)^{\prime}}+S_{k-1}^{(1)^{\prime \prime}}$, and $S_{k+1}^{(1)}=S_{k}^{(1)^{\prime \prime}}$. Therefore, equation (4) holds for $r=1$ when $n=k+1$. For any positive integer $r \leq m-L$, the event that at least $r$ banks crash can be written as $\bigcup_{j=1}^{N} A_{j}^{(r)}$, where $A_{j}^{(r)}$ is defined in equation (4). Therefore, $\triangle P_{m \mid L}(r) \equiv$ $P\left[\bigcup_{j=1}^{N} A_{j}^{(r)} \mid \bigcap_{i \in S}\left(X_{i}>Q_{i}(p)\right)\right]-P\left[\bigcup_{j=1}^{N} A_{j}^{(r)}\right]$. Thus, we can use the same way as we prove equation (4) for $r=1$ to prove that equation (4) holds for any positive integer $r \leq m-L$. 
Table 1: Summary Statistics of the Data

\begin{tabular}{|c|c|c|c|c|c|c|c|c|}
\hline Institute & Mean & Std.Dev & Skewness & Kurtosis & Min & Max & JB Test & A.D.F. Test \\
\hline $\mathrm{RBC}$ & 0.1 & 1.5 & 0.2 & 11.9 & -14.4 & 13.7 & 13778 & -56.2 \\
\hline $\mathrm{TD}$ & 0.0 & 1.7 & 0.2 & 8.5 & -13.6 & 12.3 & 5128 & -53.1 \\
\hline BNS & 0.0 & 1.6 & 0.0 & 9.5 & -14.3 & 12.2 & 7113 & -44.0 \\
\hline BMO & 0.0 & 1.6 & 0.4 & 11.2 & -13.1 & 16.7 & 11455 & -57.1 \\
\hline CIBC & 0.0 & 1.8 & -0.1 & 10.3 & -17.0 & 13.1 & 9210 & -52.3 \\
\hline $\mathrm{NB}$ & 0.0 & 1.7 & 0.1 & 12.1 & -18.2 & 13.7 & 14036 & -34.7 \\
\hline GW & 0.1 & 1.9 & -0.3 & 9.6 & -18.4 & 19.8 & 7481 & -25.9 \\
\hline $\mathrm{CW}$ & 0.1 & 1.8 & 0.4 & 16.7 & -15.3 & 10.9 & 32007 & -13.1 \\
\hline LAU & 0.0 & 1.7 & 0.1 & 11.6 & -9.3 & 12.2 & 12089 & -28.0 \\
\hline SLIFE & 0.0 & 2.2 & 0.1 & 12.6 & -15.0 & 17.9 & 9490 & -8.3 \\
\hline MLIFE & 0.0 & 2.2 & -0.4 & 16.4 & -16.6 & 16.9 & 19657 & -12.9 \\
\hline JPMORGAN & 0.0 & 2.7 & 0.3 & 14.7 & -23.2 & 22.4 & 236190 & -65.7 \\
\hline CITIG & -0.0 & 3.3 & -0.5 & 41.8 & -49.5 & 45.6 & 257220 & -34.1 \\
\hline $\mathrm{BOA}$ & 0.0 & 2.9 & -0.3 & 31.7 & -34.2 & 30.2 & 141130 & -62.1 \\
\hline WELLS & 0.0 & 2.5 & 0.9 & 28.2 & -27.2 & 28.3 & 108680 & -30.1 \\
\hline GOLDMAN & 0.0 & 2.8 & 0.4 & 12.9 & -21.0 & 23.5 & 11302 & -55.7 \\
\hline $\mathrm{AIG}$ & -0.0 & 3.9 & -3.6 & 123.9 & -93.6 & 50.7 & 249690 & -34.0 \\
\hline MORGAN & 0.0 & 3.3 & 1.3 & 47.5 & -29.9 & 62.6 & 339840 & -33.1 \\
\hline BANCORP & 0.0 & 2.3 & -0.1 & 16.7 & -20.0 & 20.6 & 3210 & -66.6 \\
\hline BNYORK & 0.0 & 2.6 & -0.1 & 18.5 & -31.7 & 22.2 & 40815 & -52.3 \\
\hline SSTATE & 0.0 & 3.1 & -0.4 & 29.1 & -89.3 & 27.3 & 11654 & -47.9 \\
\hline DEUTSCHE & 0.0 & 2.3 & 0.2 & 12.9 & -18.1 & 22.3 & 168130 & -46.6 \\
\hline BARCLAY & 0.0 & 2.8 & 1.5 & 52.3 & -23.6 & 54.9 & 417080 & -60.1 \\
\hline BNPPAR & -0.0 & 3.4 & -0.7 & 34.9 & -18.9 & 18.8 & 174120 & -54.7 \\
\hline UBS & -0.0 & 2.3 & 0.2 & 16.7 & -18.8 & 27.5 & 32038 & -16.7 \\
\hline SOCIETE & 0.0 & 2.4 & -0.1 & 9.0 & -16.9 & 18.2 & 6201 & -60.9 \\
\hline BANCO & 0.0 & 2.1 & -0.1 & 9.2 & -16.0 & 14.1 & 6168 & -61.9 \\
\hline CREDIT & 0.0 & 2.5 & 0.2 & 12.3 & -17.7 & 24.6 & 14938 & -59.6 \\
\hline COMMER & -0.0 & 2.6 & -0.2 & 15.5 & -28.2 & 19.5 & 265140 & -48.4 \\
\hline BBVA & -0.0 & 3.4 & -0.7 & 34.9 & -52.2 & 38.9 & 120460 & -11.9 \\
\hline CRESWISS & 0.0 & 2.4 & -7.1 & 61.3 & -16.9 & 23.8 & 432107 & -32.2 \\
\hline MITSUBISHI & -0.0 & 2.7 & 0.3 & 6.4 & -15.8 & 14.6 & 1090 & -44.7 \\
\hline MIZUHO & -0.1 & 3.5 & 0.2 & 6.7 & -17.7 & 17.8 & 1366 & -44.1 \\
\hline SUMIT & 0.0 & 2.5 & -0.0 & 6.2 & -18.1 & 13.2 & 17663 & -44.2 \\
\hline TSX & 0.0 & 1.1 & -0.7 & 13.8 & -9.8 & 9.4 & 20099 & -64.1 \\
\hline SP500 & 0.0 & 1.3 & -0.2 & 12 & -9.5 & 10.9 & 13878.9 & -49.6 \\
\hline E100 & 0.0 & 1.3 & -0.2 & 9.1 & -8.2 & 9.8 & 5397.4 & -30.6 \\
\hline Japan & -0.0 & 1.5 & -0.2 & 12.0 & -12.1 & 13.2 & 6375.2 & -48.4 \\
\hline
\end{tabular}

The JB test refers to the test for normality of the unconditional distribution of the returns. Data are from 3 January 1994 to 21 September 2009. The source of raw data is Data stream. 
Table 2: Extreme Corisk between Individual Banks $\left.(\%)\left(\triangle P_{1 \mid 1}(1)\right)\right)$

\begin{tabular}{|c|c|c|c|c|c|c|c|c|c|c|c|c|}
\hline & $\mathrm{RBC}$ & TD & BNS & $\mathrm{BMO}$ & CIBC & NB & $\mathrm{CW}$ & LAU & GW & MLIFE & SLIFE & Row Average \\
\hline \multicolumn{13}{|c|}{ Canadian Banks } \\
\hline $\mathrm{RBC}$ & & 33.3 & 29.2 & 33.2 & 26.7 & 18.9 & 23.1 & 15.7 & 14.8 & 20.4 & 17.3 & 23.2 \\
\hline TD & 23.5 & & 33.1 & 30.2 & 26.9 & 20 & 16.5 & 11.4 & 12.6 & 21.3 & 19.5 & 21.5 \\
\hline BNS & 33.1 & 28.6 & & 30.2 & 32.1 & 21 & 15.5 & 15.6 & 16.7 & 25.4 & 23.8 & 24.2 \\
\hline BMO & 26.3 & 31.9 & 29.4 & & 22.9 & 14.9 & 15.8 & 11.6 & 11.9 & 24 & 25.1 & 21.3 \\
\hline CIBC & 26.4 & 20.1 & 31.4 & 23.7 & & 14.9 & 12.4 & 12.6 & 15.7 & 21.9 & 22.8 & 20.1 \\
\hline NB & 26.6 & 17.8 & 28 & 22.8 & 20.2 & & 14.9 & 14.1 & 14.8 & 27.7 & 15.6 & 20.2 \\
\hline $\mathrm{CW}$ & 21.1 & 18 & 19.7 & 26.8 & 16.1 & 14.3 & & 18.9 & 24.8 & 19.4 & 15.2 & 19.4 \\
\hline Lau & 18.2 & 16.5 & 24.8 & 22.6 & 20.5 & 16.8 & 23.5 & & 12.5 & 18.5 & 16.1 & 19 \\
\hline GW & 18.8 & 16 & 24.9 & 20.1 & 24 & 16.7 & 29 & 11.7 & & 28.9 & 19.1 & 20.9 \\
\hline MLIFE & 22.7 & 21.6 & 23.3 & 18.8 & 23.7 & 21.8 & 16.5 & 11.8 & 23.7 & & 27.5 & 21.1 \\
\hline SLIFE & 23.1 & 25.1 & 27.9 & 18.2 & 27.4 & 13.5 & 14.7 & 12.3 & 17.2 & 30.5 & & 20.9 \\
\hline \multicolumn{13}{|l|}{ Column } \\
\hline Average & 23.9 & 22.8 & 27.1 & 24.6 & 24 & 17.2 & 18.5 & 13.5 & 16.4 & 23.8 & 20.2 & 21.1 \\
\hline \multicolumn{13}{|l|}{ U.S. Banks } \\
\hline JpMORGAN & 21.8 & 17.8 & 18.8 & 21.7 & 19.3 & 18.8 & 15.8 & 9.9 & 12.4 & 19 & 19.6 & 17.7 \\
\hline CTG & 19.7 & 8.1 & 14.2 & 17.5 & 17.6 & 9.4 & 13.4 & 8.7 & 6.7 & 19.4 & 14.6 & 13.7 \\
\hline BOA & 23.2 & 17.8 & 17.3 & 19.2 & 18.8 & 15.8 & 9.9 & 12.8 & 18.2 & 19.7 & 19.9 & 17.5 \\
\hline $\mathrm{AIG}$ & 19.3 & 6.8 & 15.3 & 14.4 & 15.7 & 15 & 18.8 & 7.5 & 18.9 & 23.2 & 14.9 & 15.4 \\
\hline WELLS & 25.6 & 18.3 & 20.2 & 23.2 & 27.3 & 11.6 & 15.6 & 9.4 & 16.9 & 22.7 & 19.4 & 19.1 \\
\hline MORGAN & 14.2 & 12.5 & 13.1 & 16.4 & 12.1 & 9.4 & 7.9 & 6.5 & 6.7 & 11.8 & 11 & 11.1 \\
\hline GOLDMAN & 18.5 & 13.3 & 13.1 & 14.1 & 13.2 & 5.5 & 7.3 & 8.9 & 11.1 & 11.1 & 14.7 & 11.8 \\
\hline BCORP & 20.1 & 11.7 & 16.5 & 17.3 & 19.1 & 13.7 & 19.5 & 12.4 & 15.2 & 24.1 & 12.5 & 16.5 \\
\hline NYORK & 21.3 & 15.3 & 17.7 & 22.1 & 14.3 & 11.3 & 11.1 & 8.8 & 10.4 & 13.3 & 17.8 & 14.8 \\
\hline SSTATE & 24.5 & 11 & 14.6 & 20.4 & 19.3 & 8 & 10.8 & 12.5 & 13.3 & 18.9 & 24.6 & 16.1 \\
\hline \multicolumn{13}{|l|}{ Column } \\
\hline Average & 20.8 & 13.2 & 16.1 & 18.6 & 17.6 & 11.8 & 13 & 9.7 & 12.9 & 18.3 & 16.9 & 15.4 \\
\hline \multicolumn{13}{|c|}{ European Banks } \\
\hline DEUTS & 12.0 & 8.7 & 14.8 & 10.9 & 14.9 & 8.2 & 7.0 & 5.3 & 8.1 & 17.1 & 13.8 & 10.9 \\
\hline COMMER & 8.2 & 3.7 & 10.1 & 8.2 & 9.8 & 8.5 & 6.6 & 6.5 & 2.6 & 12.5 & 5.7 & 7.5 \\
\hline BARCLAY & 13.1 & 6.1 & 13.1 & 12.4 & 14.6 & 9.5 & 4.6 & 5.4 & 9.7 & 9.5 & 7.5 & 9.5 \\
\hline UBS & 15 & 9.4 & 15 & 17.1 & 12.7 & 10.1 & 10.3 & 6.1 & 11.2 & 14.5 & 9.1 & 11.8 \\
\hline $\mathrm{BNP}$ & 10.5 & 9 & 13.5 & 9.6 & 10.2 & 7.8 & 9.9 & 3.8 & 3.8 & 12.4 & 12.5 & 9.3 \\
\hline SOCIETE & 6.8 & 4.4 & 10.6 & 7.7 & 12.0 & 6.4 & 4.4 & 6.3 & 7.3 & 9.8 & 7.7 & 7.5 \\
\hline BBVA & 14.2 & 11.7 & 15.1 & 10.2 & 20.8 & 11.5 & 12.6 & 2.5 & 13.5 & 9.7 & 9.3 & 11.9 \\
\hline CREDIT & 9.1 & 6.8 & 7.4 & 8.0 & 8.2 & 5.6 & 6.1 & 2.7 & 5.4 & 12.7 & 8.8 & 7.3 \\
\hline CSWISS & 9.4 & 7.9 & 7.4 & 9.3 & 7.0 & 6.9 & 6.8 & 3.0 & 7.9 & 12.8 & 15.7 & 8.5 \\
\hline BANCOS & 6.6 & 7.0 & 5.9 & 7.3 & 4.7 & 3.6 & 3.0 & 0.7 & 4.2 & 5.0 & 10.1 & 5.3 \\
\hline
\end{tabular}


... table 2 continued

\begin{tabular}{lcccccccccccc}
\hline \hline & RBC & TD & BNS & BMO & CIBC & NB & CW & LAU & GW & MLIFE & SLIFE & Row Average \\
\hline $\begin{array}{l}\text { Column } \\
\text { Average }\end{array}$ & 10.4 & 7.5 & 11.2 & 10 & 11.4 & 7.8 & 7.1 & 4.2 & 7.3 & 11.6 & 10.1 & $\mathbf{8 . 9}$ \\
& & & & & & & & & & & & \\
Asian Banks & & & & & & & & & & & \\
MITSUB & 5.9 & 3.6 & 5.7 & 10.3 & 12.9 & 6.5 & 6.5 & 7.2 & 9.9 & 8.6 & 8.7 & 7.8 \\
MIZUHO & 2.7 & 2.2 & 4.9 & 2.1 & 7.1 & 2.1 & 1.9 & 9.3 & 7.2 & 6.5 & 9.8 & 5.1 \\
SUMI & 2.0 & 0.3 & 3.0 & 4.1 & 5.6 & 4 & 6.4 & 4.9 & 3.4 & -0.3 & 1.8 & 3.2 \\
Column & & & & & & & & & & & & \\
Average & 3.5 & 2 & 4.5 & 5.5 & 8.5 & 4.2 & 4.9 & 7.1 & 6.8 & 4.9 & 6.7 & $\mathbf{5 . 3}$ \\
\hline \hline
\end{tabular}

The table reports the increase in the crash probability of the financial institution specified in the column when the financial institution in the row becomes crash. The crisis level is set to $p=0.05$. 
Table 3: Systemic Importance of Individual Banks $\left.(\%)\left(\triangle P_{5 \mid 1}(1)\right)\right)$

\begin{tabular}{|c|c|c|c|c|c|c|c|}
\hline & $A_{-R B C}$ & $A_{-T D}$ & $A_{-B N S}$ & $A_{-B M O}$ & $A_{-C I B C}$ & $A_{-N B}$ & Row Average \\
\hline \multicolumn{8}{|c|}{ Panel a: Canadian six-big banks } \\
\hline $\mathrm{RBC}$ & 30.6 & & & & & & 30.6 \\
\hline TD & & 29.6 & & & & & 29.6 \\
\hline BNS & & & 32.4 & & & & 32.4 \\
\hline $\mathrm{BMO}$ & & & & 29.4 & & & 29.4 \\
\hline CIBC & & & & & 26.7 & & 26.7 \\
\hline NB & & & & & & 27.0 & 27.0 \\
\hline \multicolumn{8}{|c|}{ The average value of Panel a: 29.3} \\
\hline \multicolumn{8}{|c|}{ Panel b: Canadian small banks } \\
\hline $\mathrm{CW}$ & 15.1 & 15.6 & 13.2 & 13.7 & 15.3 & 14.3 & 14.5 \\
\hline LAU & 18.5 & 20.5 & 16.5 & 18.7 & 18.3 & 14.0 & 17.7 \\
\hline \multicolumn{8}{|c|}{ The average value of Panel b: 16.1} \\
\hline \multicolumn{8}{|c|}{ Panel c: Canadian non-bank financial institutions } \\
\hline GW & 17.5 & 21.1 & 17.1 & 17.6 & 15.9 & 19.6 & 18.1 \\
\hline MLIFE & 23.5 & 24.2 & 20.1 & 20.7 & 22.2 & 21.0 & 21.4 \\
\hline SLIFE & 21.2 & 20.2 & 19.9 & 20.6 & 23.8 & 22.5 & 21.9 \\
\hline \multicolumn{8}{|c|}{ The average value of Panel c: 20.4} \\
\hline \multicolumn{8}{|c|}{ Panel d: the United-State' banks } \\
\hline JPMORGAN & 15.0 & 17.9 & 15.5 & 13.6 & 17.7 & 16.7 & 16.1 \\
\hline CITIG & 15.1 & 17.8 & 15.4 & 13.7 & 14.4 & 16.6 & 15.5 \\
\hline BOA & 16.2 & 20.4 & 16.7 & 17.2 & 14.1 & 17.9 & 17.1 \\
\hline WELLS & 17.4 & 20.6 & 19.5 & 20.1 & 17.6 & 22.0 & 19.4 \\
\hline GOLDMAN & 15.4 & 14.6 & 15.0 & 14.2 & 14.1 & 18.0 & 14.2 \\
\hline MORGAN & 14.0 & 15.6 & 14.2 & 12.5 & 13.3 & 15.6 & 15.2 \\
\hline \multicolumn{8}{|c|}{ The average value of Panel d: 16.7} \\
\hline \multicolumn{8}{|c|}{ Panel e: the European banks } \\
\hline DEUTS & 15.9 & 18.2 & 14.5 & 14.6 & 15.6 & 15.3 & 15.6 \\
\hline BNP & 11.8 & 10.4 & 10.3 & 8.3 & 13.3 & 13.7 & 11.3 \\
\hline BBVA & 14.2 & 16.7 & 14.7 & 15.7 & 11.7 & 12.1 & 14.1 \\
\hline BANCOS & 5.4 & 5.6 & 6.5 & 4.1 & 5.1 & 5.8 & 5.4 \\
\hline SOCIETE & 15.6 & 14.1 & 13.2 & 12.2 & 12.3 & 10.5 & 12.9 \\
\hline UBS & 14.9 & 16.8 & 13 & 12.1 & 11.0 & 18.1 & 14.3 \\
\hline \multicolumn{8}{|c|}{ The average value of Panel e: $\mathbf{1 2 . 3}$} \\
\hline \multicolumn{8}{|c|}{ Panel f: the Asian banks } \\
\hline MITSUB & 2.2 & 9.8 & 11.3 & 8 & 5.9 & 9.6 & 7.8 \\
\hline MIZUHO & 5.1 & 6.3 & 5.6 & 6.3 & 3.5 & 5.6 & 5.4 \\
\hline SUMIT & 5.0 & 5.1 & 4.9 & 4.1 & 2.4 & 4.5 & 4.3 \\
\hline \multicolumn{8}{|c|}{ The average value of Panel f: 5.8} \\
\hline
\end{tabular}

The table reports the increase in the crash probability that at least one bank in each group in the column become crashed when the institution in the row falls into crash. The crisis level is set as $0.05 . A_{1}=\{2,3,4,5,6\}, A_{2}=\{1,3,4,5,6\}$, $A_{3}=\{1,2,4,5,6\}, A_{4}=\{1,2,3,5,6\}, A_{5}=\{1,2,3,4,6\}, A_{6}=\{1,2,3,4,5\}$ where $1,2, \ldots, 6$ represent for the banks: RBC, TD, BNS, BMO, CIBC, and NB, respectfully. 
Table 4: Systemic Importance of Individual Banks $\left.(\%)\left(\triangle P_{5 \mid 1}(2)\right)\right)$

\begin{tabular}{|c|c|c|c|c|c|c|c|}
\hline & $A_{-R B C}$ & $A_{-T D}$ & $A_{-B N S}$ & $A_{-B M O}$ & $A_{-C I B C}$ & $A_{-N B}$ & Row Average \\
\hline \multicolumn{8}{|c|}{ Panel a: Canadian six-big banks } \\
\hline $\mathrm{RBC}$ & 35.0 & & & & & & 35.0 \\
\hline TD & & 34.1 & & & & & 34.1 \\
\hline BNS & & & 38.2 & & & & 38.2 \\
\hline BMO & & & & 30.9 & & & 30.9 \\
\hline CIBC & & & & & 29.2 & & 29.2 \\
\hline NB & & & & & & 28.1 & 28.1 \\
\hline \multicolumn{8}{|c|}{ the average of Panel a: 32.5} \\
\hline \multicolumn{8}{|c|}{ Panel b: Canadian small banks } \\
\hline $\mathrm{CW}$ & 19.7 & 18.2 & 18.4 & 16.5 & 19 & 18.9 & 18.4 \\
\hline LAU & 22.1 & 19.2 & 18.8 & 18.1 & 20.8 & 20.7 & 19.9 \\
\hline \multicolumn{8}{|c|}{ The average of panel b: 19.2} \\
\hline \multicolumn{8}{|c|}{ Panel c: Canadian non-bank financial institutions } \\
\hline GW & 23.4 & 19.3 & 18.5 & 21.7 & 17.3 & 21.1 & 20.2 \\
\hline MLIFE & 19.5 & 17.3 & 20.6 & 21.7 & 19.5 & 20.6 & 19.5 \\
\hline SLIFE & 20.7 & 18.4 & 19.7 & 20.8 & 16 & 21.9 & 19.9 \\
\hline \multicolumn{8}{|c|}{ The average of Panel c: 19.8} \\
\hline \multicolumn{8}{|c|}{ Panel d: The United State's banks } \\
\hline JPMORGAN & 16.6 & 18.7 & 20.2 & 17.6 & 18.6 & 17.1 & 18.1 \\
\hline CITIG & 13.6 & 15.2 & 16.9 & 15.7 & 14.4 & 16.3 & 15.3 \\
\hline BOA & 16.6 & 18.3 & 20.2 & 18.8 & 17.4 & 17.1 & 18.0 \\
\hline WELLS & 22.7 & 24.6 & 25.4 & 23.7 & 20.6 & 23.2 & 23.3 \\
\hline GOLDMAN & 13.0 & 16.5 & 15.4 & 15.7 & 16.3 & 13.8 & 15.1 \\
\hline MORGAN & 11.4 & 14.1 & 12.5 & 12.4 & 12.2 & 11.9 & 12.4 \\
\hline \multicolumn{8}{|c|}{ The average of Panel d: 17.5} \\
\hline \multicolumn{8}{|c|}{ Panel e: The European banks } \\
\hline DEUTS & 15.0 & 12.3 & 13.5 & 13.1 & 11.8 & 16.0 & 13.6 \\
\hline BNP & 12.1 & 13.2 & 11.8 & 13.2 & 10.7 & 12.1 & 12.1 \\
\hline BBVA & 1.7 & 14.7 & 13.3 & 15.8 & 14.2 & 10.3 & 13.2 \\
\hline BANCOS & 4.5 & 4.9 & 5.8 & 4.8 & 7.1 & 3.6 & 5.1 \\
\hline SOCIETE & 8.9 & 9.1 & 7.6 & 9.1 & 6.7 & 8.8 & 8.3 \\
\hline UBS & 12.3 & 11.5 & 15.1 & 13.4 & 13.0 & 15.5 & 13.4 \\
\hline \multicolumn{8}{|c|}{ The average of panel e: 10.9} \\
\hline \multicolumn{8}{|c|}{ Panel f: The Asian banks } \\
\hline MITSUB & 9.8 & 10.6 & 9 & 9.8 & 7.9 & 9.5 & 9.4 \\
\hline MIZUHO & 4.1 & 4.8 & 3.3 & 4.1 & 4 & 5.6 & 4.3 \\
\hline SUMIT & 5.3 & 5.2 & 5.3 & 4.8 & 4.7 & 5.2 & 5.0 \\
\hline \multicolumn{8}{|c|}{ Panel: The average of Panel f: 6.2} \\
\hline
\end{tabular}

The table reports the increase in the crash probability that at least two banks in each group in the column become crashed when the institution in the row falls into crash. The crisis level is set as 0.05. $A_{1}=\{2,3,4,5,6\}, A_{2}=\{1,3,4,5,6\}$, $A_{3}=\{1,2,4,5,6\}, A_{4}=\{1,2,3,5,6\}, A_{5}=\{1,2,3,4,6\}, A_{6}=\{1,2,3,4,5\}$ where $1,2, \ldots, 6$ represent for the banks: RBC, TD, BNS, BMO, CIBC, and NB, respectfully. 
Table 5: Systemic Importance of Individual Banks $\left.(\%)\left(\triangle P_{5 \mid 1}(3)\right)\right)$

\begin{tabular}{|c|c|c|c|c|c|c|c|}
\hline & $A_{-R B C}$ & $A_{-T D}$ & $A_{-B N S}$ & $A_{-B M O}$ & $A_{-C I B C}$ & $A_{-N B}$ & Row Average \\
\hline \multicolumn{8}{|c|}{ Panel a: Canadian six-big banks } \\
\hline RBC & 34.4 & & & & & & 34.4 \\
\hline TD & & 35.2 & & & & & 35.2 \\
\hline BNS & & & 37.9 & & & & 37.9 \\
\hline BMO & & & & 31.5 & & & 31.5 \\
\hline CIBC & & & & & 29.3 & & 29.3 \\
\hline NB & & & & & & 27.4 & 27.4 \\
\hline \multicolumn{8}{|c|}{ The average of Panel a: 32.6} \\
\hline \multicolumn{8}{|c|}{ Panel b: Canadian small banks } \\
\hline $\mathrm{CW}$ & 20.2 & 21.4 & 22.0 & 20.1 & 22.7 & 20.9 & 21.2 \\
\hline Lau & 24.3 & 22.8 & 26.4 & 24.5 & 24.4 & 22.3 & 24.1 \\
\hline \multicolumn{8}{|c|}{ The average of Panel b: 22.6} \\
\hline \multicolumn{8}{|c|}{ Panel c: Canadian non-bank financial institutions } \\
\hline GW & 21.6 & 21.7 & 20.6 & 20.2 & 23.3 & 21.1 & 21.4 \\
\hline MLIFE & 28.0 & 24.3 & 28.3 & 25.5 & 26.1 & 24.5 & 26.1 \\
\hline SLIFE & 26.4 & 24.2 & 25.1 & 25.4 & 22.8 & 25.1 & 24.8 \\
\hline \multicolumn{8}{|c|}{ The average of Panel c: 24.9} \\
\hline \multicolumn{8}{|c|}{ Panel d: The United State's banks } \\
\hline JpMORGAN & 18.5 & 19.5 & 20.2 & 17.1 & 20.7 & 20.2 & 19.3 \\
\hline CITIG & 13.1 & 16.1 & 14.7 & 13.8 & 16.1 & 15.5 & 14.8 \\
\hline BOA & 18.5 & 18.2 & 17.8 & 18.2 & 19.4 & 20.1 & 18.7 \\
\hline WELLS & 21.9 & 23.1 & 22.4 & 21.8 & 20.4 & 24.0 & 22.3 \\
\hline GOLDMAN & 12.5 & 15.1 & 16.2 & 12.9 & 15.5 & 14.9 & 14.5 \\
\hline MORGAN & 13.1 & 11.6 & 13.6 & 10.5 & 14.9 & 12.2 & 12.6 \\
\hline \multicolumn{8}{|c|}{ The average of Panel d: 17.7} \\
\hline \multicolumn{8}{|c|}{ Panel e: The European banks } \\
\hline DEUTS & 12.6 & 11.7 & 13.6 & 12.6 & 11.2 & 12.1 & 12.3 \\
\hline BNP & 12.0 & 10.9 & 10.8 & 12.9 & 11.4 & 12.5 & 11.7 \\
\hline BBVA & 14.6 & 15.6 & 12.3 & 15.6 & 14.1 & 15.1 & 14.5 \\
\hline BANCOS & 5.6 & 6.6 & 4.4 & 5.7 & 6.2 & 7.8 & 6.1 \\
\hline SOCIETE & 6.3 & 7.3 & 7.6 & 6.3 & 7.8 & 7.8 & 7.1 \\
\hline UBS & 13.4 & 14.4 & 13.9 & 13.3 & 14.8 & 14.9 & 14.1 \\
\hline \multicolumn{8}{|c|}{ The average of Panel of e: 10.8} \\
\hline \multicolumn{8}{|c|}{ Panel f: The Asian banks } \\
\hline MITSUB & 8.1 & 9.1 & 9.2 & 7.1 & 7.0 & 8.1 & 8.1 \\
\hline MIZUHO & 5.1 & 2.2 & 2.2 & 3.7 & 1.5 & 2.9 & 2.9 \\
\hline SUMIT & 2.8 & 3.9 & 3.8 & 2.8 & 2.3 & 2.9 & 3.1 \\
\hline \multicolumn{8}{|c|}{ The average of Panel f: 4.7} \\
\hline
\end{tabular}

The table reports the increase in the crash probability that at least three banks in each group in the column become crashed when the institution in the row falls into crash. The crisis level is set as 0.05. $A_{1}=\{2,3,4,5,6\}, A_{2}=\{1,3,4,5,6\}$, $A_{3}=\{1,2,4,5,6\}, A_{4}=\{1,2,3,5,6\}, A_{5}=\{1,2,3,4,6\}, A_{6}=\{1,2,3,4,5\}$ where $1,2, \ldots, 6$ represent for the banks: RBC, TD, BNS, BMO, CIBC, and NB, respectfully. 
Table 6: Systemic Importance of Individual Banks $\left.(\%)\left(\triangle P_{5 \mid 1}(4)\right)\right)$

\begin{tabular}{|c|c|c|c|c|c|c|c|}
\hline & $A_{-R B C}$ & $A_{-T D}$ & $A_{-B N S}$ & $A_{-B M O}$ & $A_{-C I B C}$ & $A_{-N B}$ & Row Average \\
\hline \multicolumn{8}{|c|}{ Panel a: Canadian six-big banks } \\
\hline $\mathrm{RBC}$ & 33.4 & & & & & & 33.4 \\
\hline TD & & 31.0 & & & & & 31.0 \\
\hline BNS & & & 32.5 & & & & 32.5 \\
\hline BMO & & & & 29.6 & & & 29.6 \\
\hline CIBC & & & & & 27.4 & & 27.4 \\
\hline NB & & & & & & 26.1 & 26.1 \\
\hline \multicolumn{8}{|c|}{ The average of Panel a: 30} \\
\hline \multicolumn{8}{|c|}{ Panel b: Canadian small banks } \\
\hline $\mathrm{CW}$ & 21.7 & 20.2 & 24.5 & 21.5 & 24.8 & 24.1 & 22.8 \\
\hline Lau & 21.8 & 23.6 & 18.4 & 20.4 & 20.7 & 25.5 & 22.7 \\
\hline \multicolumn{8}{|c|}{ The average of Panel b: 23.3} \\
\hline \multicolumn{8}{|c|}{ Panel c: Canadian non-bank financial institutions } \\
\hline GW & 21.1 & 21.2 & 23 & 21.1 & 21.5 & 19.7 & 21.2 \\
\hline MLIFE & 22.4 & 25.9 & 23.6 & 27.8 & 23.3 & 25.3 & 24.7 \\
\hline SLIFE & 23 & 24.1 & 24.9 & 27.1 & 23.4 & 23.7 & 24.3 \\
\hline \multicolumn{8}{|c|}{ The average of Panel c: 23.4} \\
\hline \multicolumn{8}{|c|}{ Panel d: The United State's banks } \\
\hline JpMORGAN & 18.1 & 17.9 & 16 & 19.1 & 18.6 & 20.1 & 18.3 \\
\hline CITIG & 14.9 & 16.7 & 15.3 & 15.6 & 14.3 & 15.3 & 15.4 \\
\hline BOA & 15.7 & 17.9 & 16 & 14.3 & 17.4 & 16.5 & 16.3 \\
\hline WELLS & 22.8 & 24.1 & 22.9 & 21.4 & 23.3 & 23.9 & 23.0 \\
\hline GOLDMAN & 9.5 & 12.5 & 9.3 & 12.7 & 8.9 & 13.3 & 11.0 \\
\hline MORGAN & 13.8 & 14.6 & 13.1 & 13.5 & 14.3 & 14.2 & 13.9 \\
\hline \multicolumn{8}{|c|}{ The average of Panel d: 16.8} \\
\hline \multicolumn{8}{|c|}{ Panel e: The European banks } \\
\hline DEUTS & 11.1 & 11 & 9.6 & 11.9 & 10.1 & 11.4 & 10.8 \\
\hline BNP & 9.7 & 9.8 & 9.2 & 10.7 & 8.7 & 11.3 & 9.9 \\
\hline BBVA & 13.4 & 12.5 & 10.9 & 14.4 & 11.5 & 13 & 12.6 \\
\hline BANCOS & 7.3 & 6.3 & 5.9 & 8.1 & 6.4 & 6.6 & 6.7 \\
\hline SOCIETE & 6.4 & 6.5 & 5 & 7.4 & 5.5 & 6.9 & 6.2 \\
\hline UBS & 11.2 & 12.1 & 11.6 & 11.1 & 11.0 & 12.7 & 11.6 \\
\hline \multicolumn{8}{|c|}{ The average of Panel e: 9.4} \\
\hline \multicolumn{8}{|c|}{ Panel f: The Asian banks } \\
\hline MITSUB & 8.6 & 7.6 & 7.5 & 7.6 & 7.8 & 6.8 & 7.6 \\
\hline MIZUHO & 3.1 & 3.8 & 3.7 & 3.8 & 2.3 & 3.0 & 3.2 \\
\hline SUMIT & 2.7 & 2.1 & 2.2 & 2.1 & 2.2 & 1.6 & 2.1 \\
\hline \multicolumn{8}{|c|}{ The average of Panel f: 4.3} \\
\hline
\end{tabular}

The table reports the increase in the crash probability that at least four banks in each group in the column become crashed when the institution in the row falls into crash. The crisis level is set as 0.05. $A_{1}=\{2,3,4,5,6\}, A_{2}=\{1,3,4,5,6\}$, $A_{3}=\{1,2,4,5,6\}, A_{4}=\{1,2,3,5,6\}, A_{5}=\{1,2,3,4,6\}, A_{6}=\{1,2,3,4,5\}$ where $1,2, \ldots, 6$ represent for the banks: RBC, TD, BNS, BMO, CIBC, and NB, respectfully. 


\section{Table 7: Systemic Importance of Individual Banks $(\%)\left(\triangle P_{5 \mid 1}(5)\right)$}

\begin{tabular}{|c|c|c|c|c|c|c|c|}
\hline & $A_{-R B C}$ & $A_{-T D}$ & $A_{-B N S}$ & $A_{-B M O}$ & $A_{-C I B C}$ & $A_{-N B}$ & Row Average \\
\hline \multicolumn{8}{|c|}{ Panel a: Canadian six-big banks } \\
\hline $\mathrm{RBC}$ & 23.8 & & & & & & 23.8 \\
\hline $\mathrm{TD}$ & & 24.6 & & & & & 24.6 \\
\hline BNS & & & 23.1 & & & & 23.1 \\
\hline BMO & & & & 20.7 & & & 20.7 \\
\hline $\mathrm{CIBC}$ & & & & & 18.7 & & 18.7 \\
\hline NB & & & & & & 21.5 & 21.5 \\
\hline \multicolumn{8}{|c|}{ The average of Panel a: 22.1} \\
\hline \multicolumn{8}{|c|}{ Panel b: Canadian small banks } \\
\hline $\mathrm{CW}$ & 14.4 & 18.1 & 14.3 & 13.5 & 14.2 & 17.8 & 15.3 \\
\hline LAU & 10.7 & 16.7 & 10.6 & 11.4 & 10.9 & 15.2 & 12.7 \\
\hline \multicolumn{8}{|c|}{ The average of Panel b: 14} \\
\hline \multicolumn{8}{|c|}{ Panel c: Canadian non-bank financial institutions } \\
\hline GW & 16.7 & 16.8 & 16.6 & 15.7 & 15.2 & 22.1 & 17.1 \\
\hline MLIFE & 13.3 & 12.5 & 12.3 & 14.3 & 13.4 & 17.3 & 13.9 \\
\hline SLIFE & 14.5 & 16.2 & 14.5 & 15.7 & 15.5 & 18.6 & 15.8 \\
\hline \multicolumn{8}{|c|}{ The average of Panel c: 15.6} \\
\hline \multicolumn{8}{|c|}{ Panel d: The United State's banks } \\
\hline JpMORGAN & 12.5 & 13.2 & 12.5 & 12.8 & 12.3 & 16.8 & 13.4 \\
\hline CTIGI & 10.1 & 12.7 & 10.1 & 10.8 & 9.7 & 13.3 & 11.1 \\
\hline $\mathrm{BOA}$ & 11.3 & 12.1 & 11.3 & 12.8 & 11.1 & 13.2 & 11.9 \\
\hline WELLS & 15.9 & 15.7 & 15.9 & 16.3 & 18.2 & 20.6 & 17.1 \\
\hline GOLDMAN & 9.1 & 13.8 & 9.2 & 8.5 & 16.2 & 16.6 & 12.2 \\
\hline MORGAN & 11.3 & 9.4 & 11.3 & 12.5 & 10.8 & 14.4 & 11.6 \\
\hline \multicolumn{8}{|c|}{ The average of Panel d: 12.8} \\
\hline \multicolumn{8}{|c|}{ Panel e: The European banks } \\
\hline DEUTS & 2.9 & 3.8 & 2.9 & 2.9 & 2.4 & 3.7 & 3.1 \\
\hline BNP & 1.0 & 2.1 & 1.1 & 1.2 & 1.6 & 0.7 & 1.3 \\
\hline BBVA & 7.9 & 6.9 & 7.9 & 6.9 & 6.9 & 7.8 & 7.4 \\
\hline BANCOS & 1.2 & 0.5 & 1.3 & 1.2 & 1.5 & 0.3 & 1.0 \\
\hline SOCIETE & 0.4 & 1.3 & 0.5 & 0.4 & 0.2 & 1.6 & 0.7 \\
\hline UBS AG & 4.5 & 6.6 & 4.5 & 5.1 & 5.5 & 6.7 & 5.4 \\
\hline \multicolumn{8}{|c|}{ The average of Panel e: $\mathbf{3 . 2}$} \\
\hline \multicolumn{8}{|c|}{ Panel f: Asian banks } \\
\hline MITSUB & 2.2 & 4.3 & 2.3 & 2.2 & 3.3 & 4.5 & 3.1 \\
\hline MIZUHO & 1.2 & 1.9 & 1.3 & 1.2 & 2.6 & 1.7 & 1.6 \\
\hline SUMIT & 1.3 & 2.4 & 0.8 & 1.1 & 1.8 & 0.9 & 1.3 \\
\hline \multicolumn{8}{|c|}{ The average of Panel $f: 2$} \\
\hline
\end{tabular}

The table reports the increase in the crash probability that all five banks in each group in the column become crashed when the institution in the row falls into crash. The crisis level is set as 0.05. $A_{1}=\{2,3,4,5,6\}, A_{2}=\{1,3,4,5,6\}$, $A_{3}=\{1,2,4,5,6\}, A_{4}=\{1,2,3,5,6\}, A_{5}=\{1,2,3,4,6\}, A_{6}=\{1,2,3,4,5\}$ where $1,2, \ldots, 6$ represent for the banks: RBC, TD, BNS, BMO, CIBC, and NB, respectfully. 
Figure 1: $\Delta \mathrm{P}_{10 \mid 1}(10)$ and Average of Individual Corisk

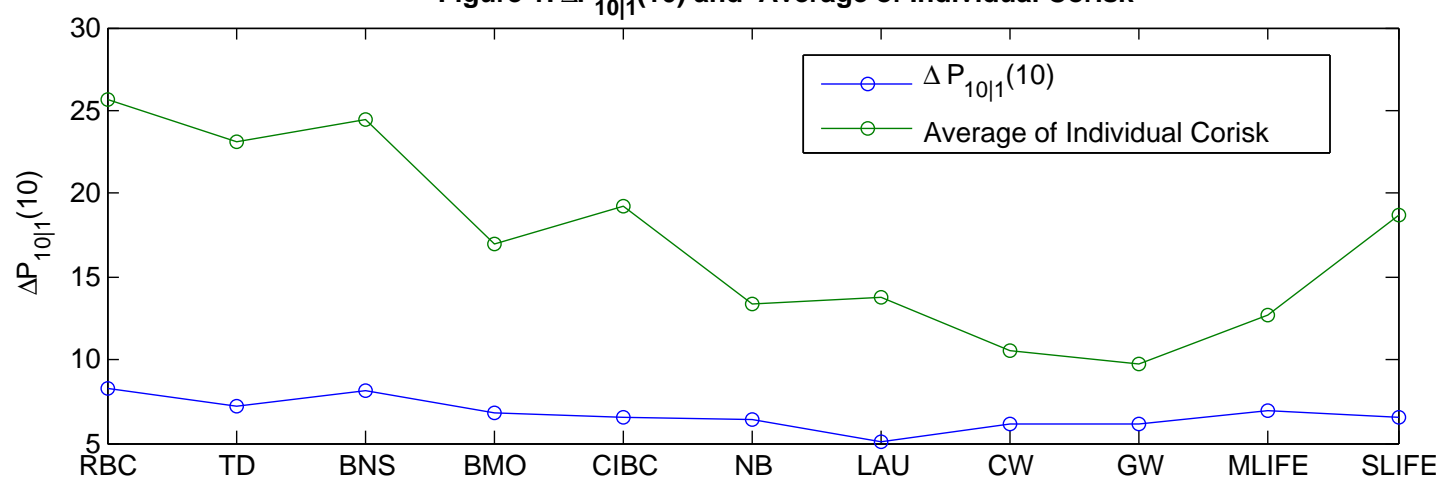

Figure 2: Extreme Corisk between the Canadian Financial System and Individual Financial Institutions

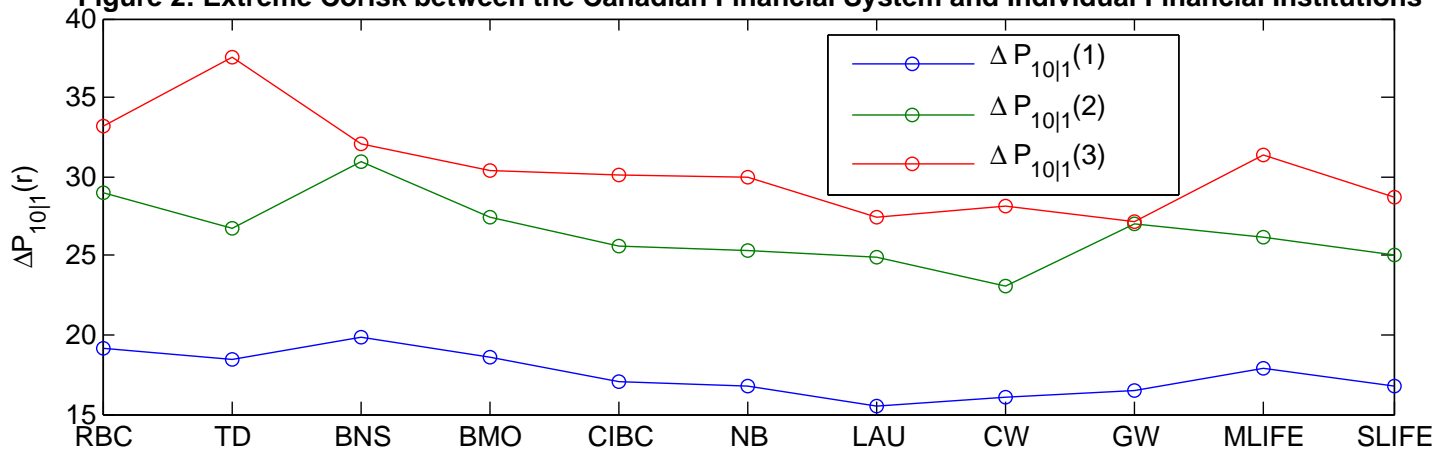

Figure 1 reports the increase in the risk that all other financial institutions become crashed when a specific institution falls into crash. For comparision, the average of the extreme Corisk between this specific institution and all other institutions is also reported in this figure. Figure 2 reports the increase in the risk from the simultaneous collapse of at leats $r(r=1,2,3)$ institution conditional on the collapse of a specific institution. 

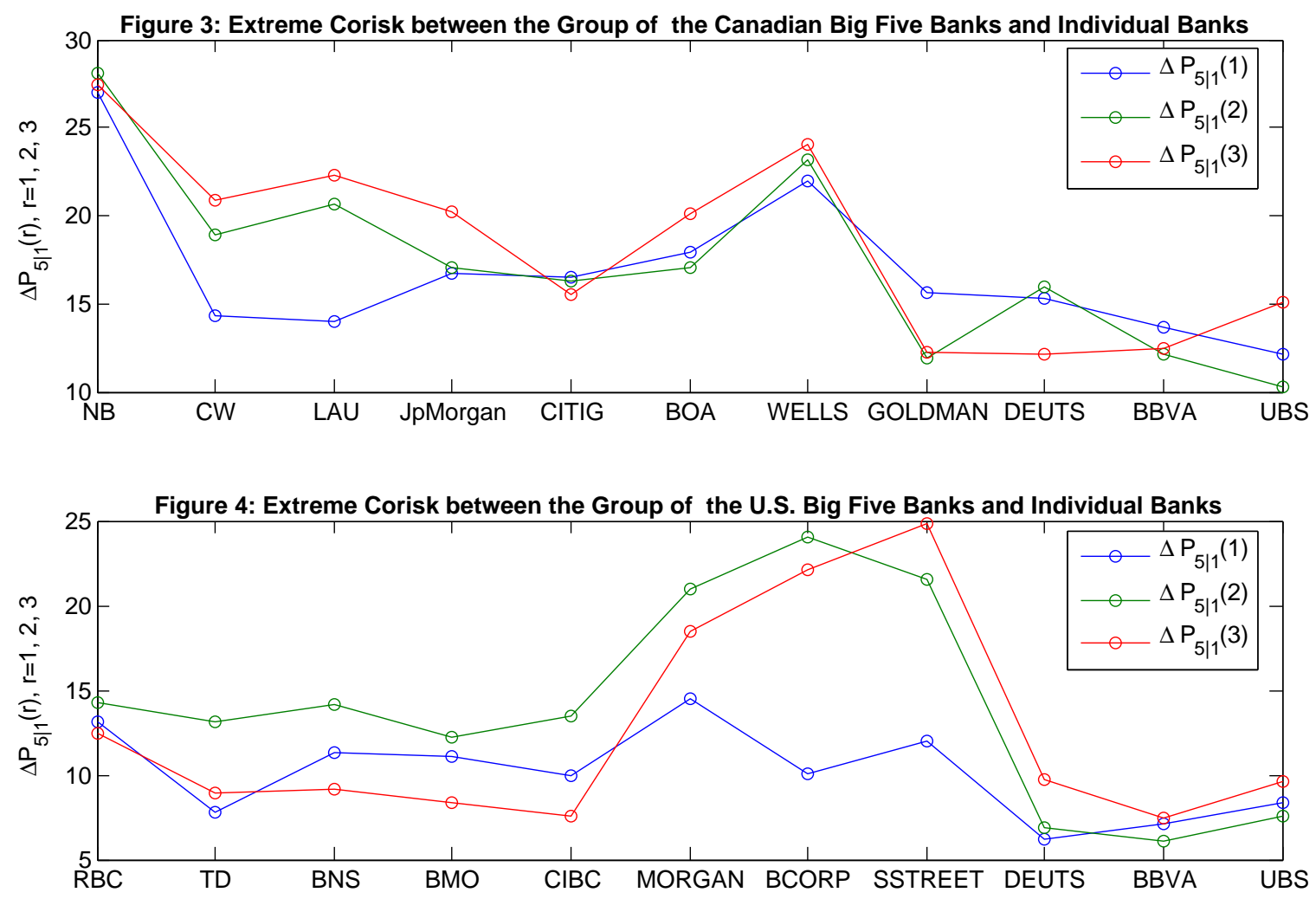

Figure 3 reports the increase in the crash probability that at least $r$ banks of the big five Canadian banks become crashed when one bank (labeled in horizontal axis) crashes $(r=1,2,3)$. Figure 4 reports the incraese in the crash probability that at least $r$ banks of the big five U.S. banks become crashed when one bank (labeled in horizontal axis) crashes $(r=1,2,3)$. 


\section{References}

[1] Adrian, T. and M. Brunnermeier (2010) "CoVaR. ", Federal Reserve Bank of New York Staff Report $348,2010$.

[2] Allenspach, N. and P. Monnin (2006) "International Integration, Common Exposures and Systemic Risk in the Banking Sector: Am empirical Investigation,” Swiss National Bank, Working Paper.

[3] Avesani, R., Pascual, A. G., and J. Li (2006) “ A New Risk Indicator and Stress Testing Tool: A Multifactor Nth-to-default CDS Basket. IMF Working Paper No. 06/105.

[4] Chan-Lau, J. and T. Gravelle (2005)“'A New Indicator of Financial and Nonfinancial Corporate Sector Vulnerability," IMF Working Paper, N. 231.

[5] Chan-Lau, J., Mitra, S. and L. Li (2007) "Contagion Risk in the International Banking System and Implications for London as a Global Financial Center," IMF Working Paper, N. 74.

[6] De Jonghe O. (2009) "Back to the Basics in Banking? A Micro-Analysis of Banking System Stability" Journal of Financial Intermediation (Forthcoming).

[7] De Haan, L., D.W. Jansen, K.Koedijk, and C.G.de Vries (1994) "Safety first Portfolio Selection, Extreme Value Theory and Long Run Asset Risks, " in J.Galambos (Ed.), Proceedings from a Conference on Extreme Value Theory and Applications (Kluwer press).

[8] Danielsson, J. and C. de Vries (1997) “ Tail Index and Quantile Estimation with Very High Frequency Data," Journal of Empirical Finance, 4, 241-257.

[9] Elsinger, H. and A. Lehar (2005) "Systemically Important Banks: An Analysis for the European Banking System,” Oesterreichische National Bank.

[10] Goldie, C. and R. Smith (1987)“ Slow Variation with Remainder: Theory and Applications,' Quarterly Journal of Mathematics, 38, 45-71.

[11] Hartmann, P., S. Straetmans, and C. De Vries (2005)“ Banking system stability, a cross-atlantic perdpective," European central bank, Working paper No. 527,2005.

[12] Hill, B. (1975) "A simple general approach to inference about the tail of a distribution," The Annals of Statistics, 3(5), 1163-1173.

[13] Illing, M. and Y.Liu (2006) " Measuring Financial Stress in a Developed Country: An Application to Canada, " Journal of Fianacial Stability 2 (3): 243-65.

[14] Jansen, D. and C. de Vries (1991) "On the Frequency of Large Stock Returns: Putting Booms and Buts into Perspective," Review of Economics and Statistics, 73, 19-24.

[15] Kaufman, G. (1988) “ Bank Runs: Causes, Benefits and Costs,” Cato Journal, 7(3), 559-587.

[16] Kullback, J.(1959)“ Information Theory and Statistics” New York, John Wiley.

[17] Lehar, A.(2005)“ Measuring systemic risk: A risk mangement approach "Journal of Banking Fiance $29,2577-2603$.

[18] Ledford, A. and A. Tawn (1996) "Statistics for Nearly Independence in Multivariate Extreme Values," Biometrika, 83, 169-187. 
[19] Merton, R.C. (1974) "On the pricing of corporate debt: the risk structure of interest rates," Journal of Finance, 29, 449-470.

[20] Poon, S. and J. Tawn (2004)"Extreme value dependence in financial markets: Diagnostics, models, and financial implications ," Review of Financial Studies, 17(2), 581-610.

[21] Quintons, C., Z. Fan and P.Phillips (2001) "Structural Change Tests in Tail Behaviour and the asian Crisis, ", Review of Fianacial Strudeis, 68, 633-663.

[22] Saunders, A., and B. Wilson (1996) "Contagious Bank Runs: Evidence from the 1929-33 Period ," Journal of Financial Intermediations, 5(4), 409-423.

[23] Segoviano, M. and C. Goodhart (2009)“Banking Stability Measures," Technical report, IMF Working Paper 09/04, 2009.

[24] Straetmans, S.T.M., W.F.C. Verschoor and C.C.P. Wolff (2008) "Extreme US Stock Market Fluctuations in the Wake of 9/11," Journal of Applied Econometrics, 23, 17-42.

[25] Tarashev, N., C. Borio, and K. Tsatsaronis (2009) "The systemic importance of financial institutions," , BIS Quarterly Review, September 2009, 75-87.

[26] Zhou C. (2010) "Are Banks too Big to Fail? Measuring Systemic Importance of Finacial Institutions" International Journal of Central Banking 6(4), 205-250. 